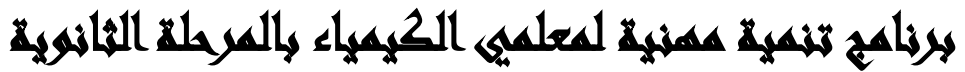

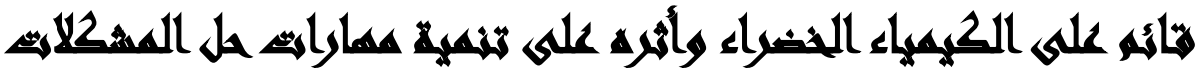

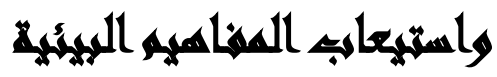

[10]

محمد سمير عبد المعز (')- أسامة جبريل أحمد(')- سحر ابراهيم محسن(ץ)

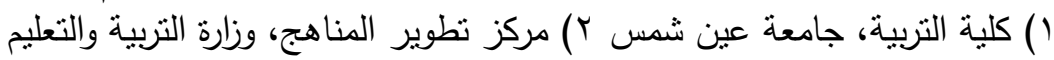

\section{المستخلص}

هدف البحث الى تصميم برنامج تدريبي للتتمية المهنية لمعلمي الكيمياء بالمرحلة الثانوية

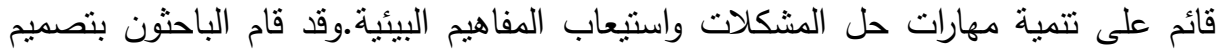

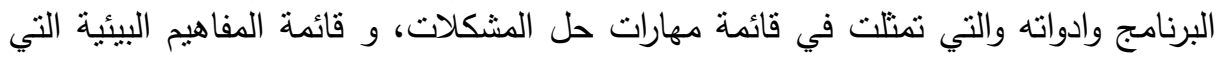

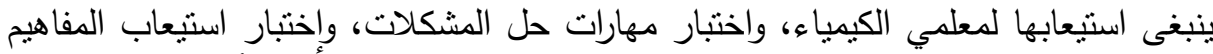

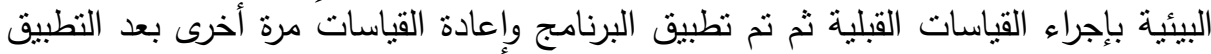

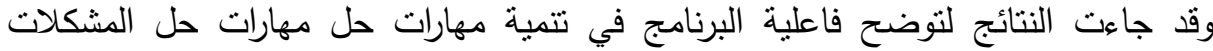

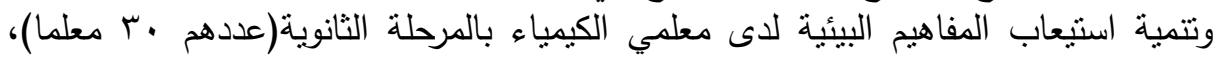

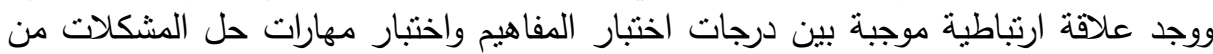

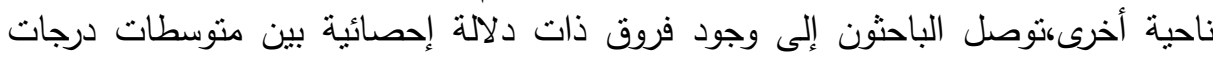

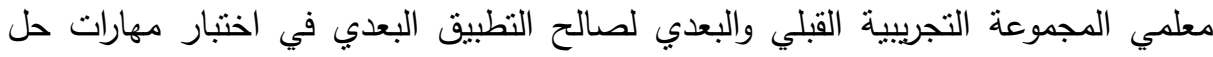

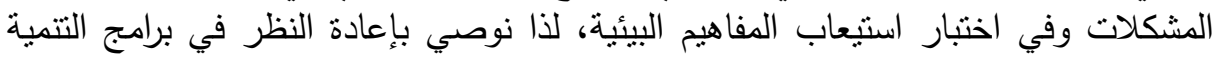

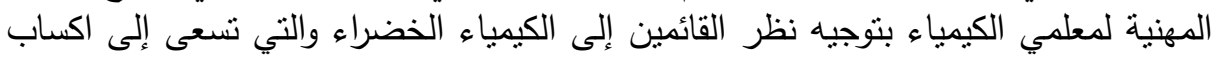

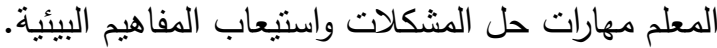

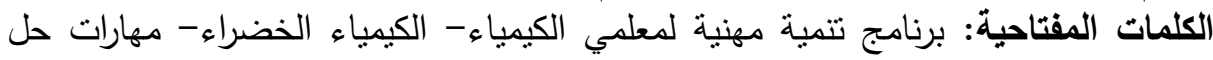
المشكلات- استيعاب المفاهيم البيئية.

\section{المهتصهاد}

يواجه المجتمع تحديات علميه وتكنولوجيه واقتصادية متعددة ومتثابكة وتتطلب مواجه

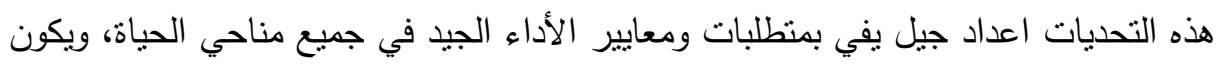

$$
\begin{aligned}
& \text { قادرا على تلبية منطلبات المجتمع وحل مشكلاته وتطوير جودة حياته. }
\end{aligned}
$$

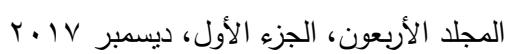


تعد التربية وسيلة المجتمع لإعداد هذه الأجيال من خلال تتمية الفردتتمية شاملة متكاملة

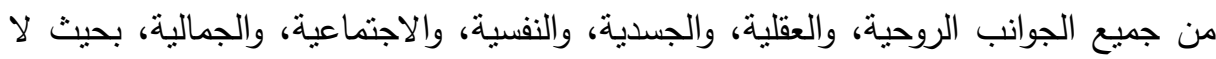

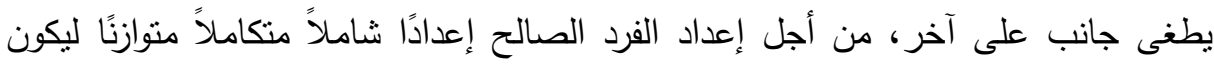

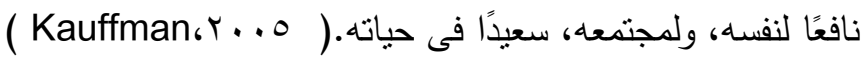
لذا كانت الحاجة إلى الإنماء المهني حاجة قائمة باستمرار، نظرًا لأن المعلم لا يمكن أن أن يعيش مدى حياته، بمجموعة محدودة من المعارف والمهارات، ونظرا للتقدم المعرفي الهائل

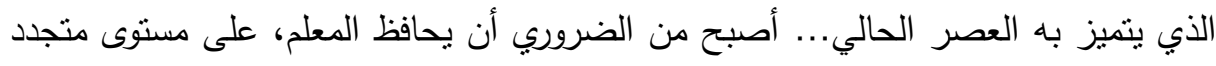
من المعلومات والمهارات والاتجاهات الحديثة في طرائق التعليم وتقنياته ... وبذا يكون التعليم

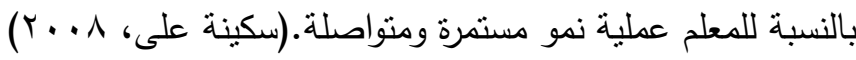
لذا تتضح الحاجة لعمل برامج تدريب المعلمين على اساليب وطرائق تساعدهم على إلى مواجهة المواقف والمشكلات التي قد نواجهم في حياتهم العملية والتدريسية للمواد المختلفة ومنها الكيمياء سواء أكان ذلك على مستوى العمل. فعندما يواجه المعلم مشكلة ما فعليه اتخاذ

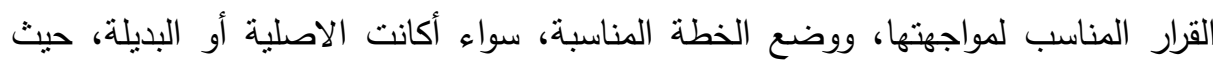
تتضمن الخطة الخطوات التي عن طريقها يمكن حل المشكلة.(مجدي عزيز ، ب. . r) في هذا السياق فقد اسفرت نتائج العديد من الدراسات، مثل دراسة ( محمد حمزة،

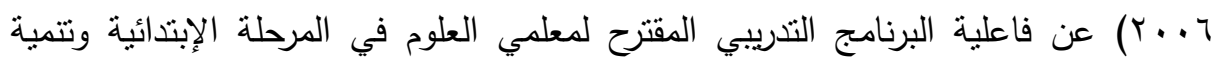
الجوانب المعرفية المرتبطة بالمهارات التنريسية، ودراسة (Karen et, al (2008)عن فاعلية برامج التنمية المهنية للمعلمين في رفع الإنجازات والمهارات العلمية لدي تلاميذهم، ودراسة (أماني عبد العزيز ، • ب) عن فاعلية البرنامج التدريبي في تتمية المفاهيم العلمية في مجال

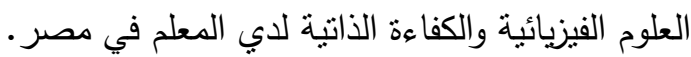

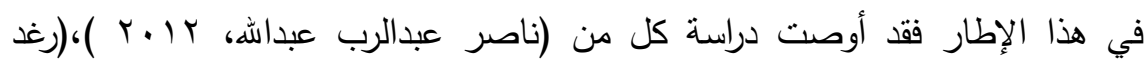

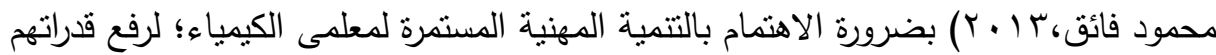

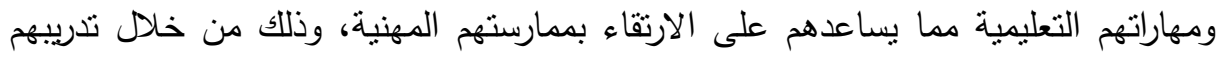


على استراتيجيات تدريس فاعلة تتاسب طبيعة مادة الكيمياء وتدريبهم على استخدام اساليب جيدة في تقييم مستوى طلابهم.

قد أسهمت الكيمياء بالدور الأعظم فى هذه النهضة الحضارية التى شملت شتى مجالات الحياة ثم تحول هذا التتاغم بين الإنسان والبيئة إلى عداء مرة أخرى. فقد أسرف الإنسان إسرافا لئهاء

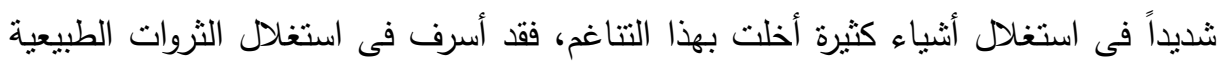

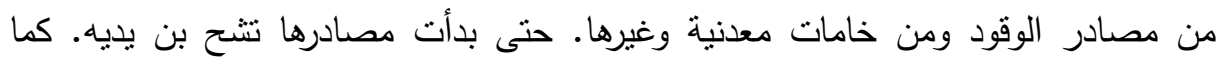

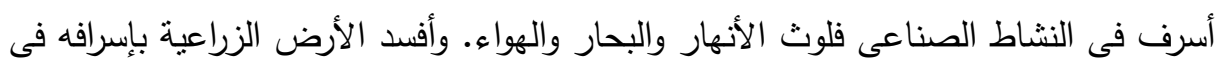
استخدام المخصبات والمبيدات.(محمد سمير ، V. V. T) تعد الكيمياء الخضراء من الاتجاهات الحديثة للعلم التى بدأ العالم يلجأ إليها وبهتم بها وبمبادئها التى تهدف إلى تصميم وإنتاج مواد كيماوية تعود بالخير على البيئة وكما يدعو هذا لهاهي

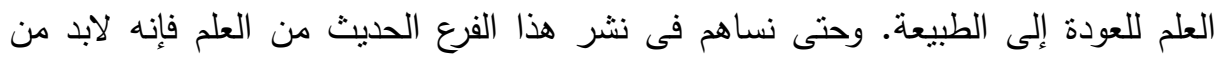
تضمينه فى المناهج الدراسية بالمرحلة الثانوية وذللك لتنمية قدرات التناميذ على حل مشكلات النلوث الناتجه من التفاعلات والصناعات الكيميائية. في هذا الإطار فقد توصلت دراسة (Hjeresen, 2002) إلى أن الطلاب مهتمون بالحفاظ على عالمهم المحيط وذللك من خلال تدارسهم للكيمياء الخضراء والتي تسعي إلي

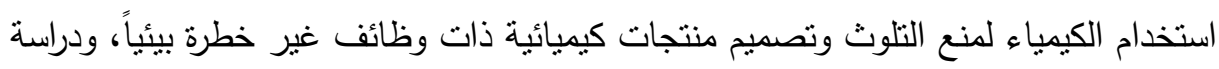

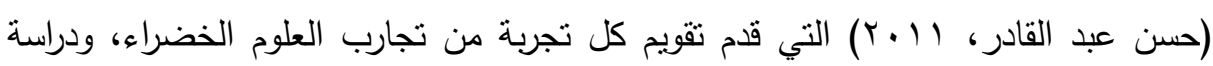

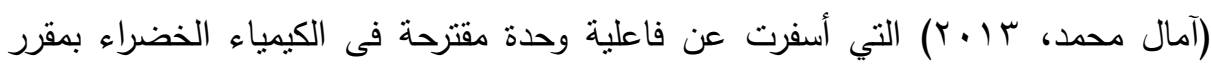
الكيمياء في تتمية المفاهيم والاتجاهات البيئية للطلاب.

بالنظر إلي مادة الكيمياء فى المرحلة الثانوية بجمهورية مضر العبهاء العربية نجد إنها تتصف بوجود علاقات متداخلة بين المفاهيم العلمية وتحويلات كثيرة وتطبيقات متعددة على المبادئ الكيميائية مما يزيد من صعوبة تعلمها وإنخفاض قدرة المعلمين على حل مشكلاتها، وأن هناك مأك

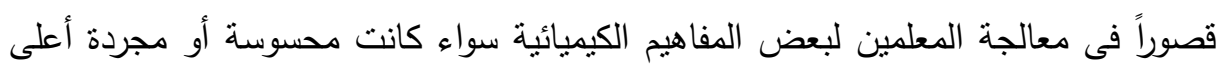

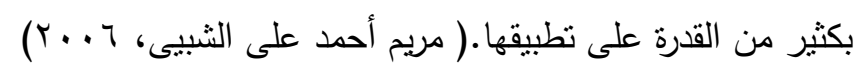


تحتل مهارات حل المشكلات مكانة مرتفعة لاى التربوبين في الوقت الحالي كأحد النماذج التربوية الحديثة، فنتمية نلك المهارات من أهم الأهداف التي نسعى الي تحقيقها أثناء

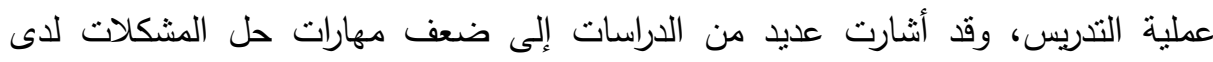

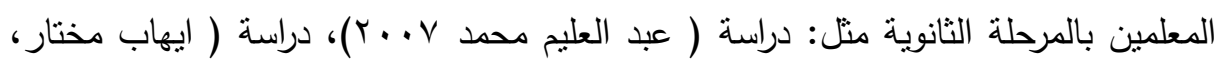

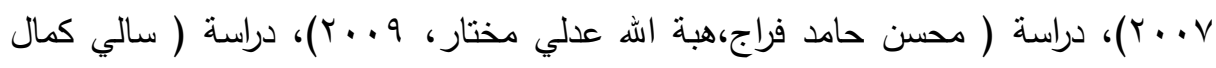

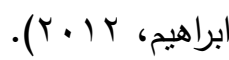

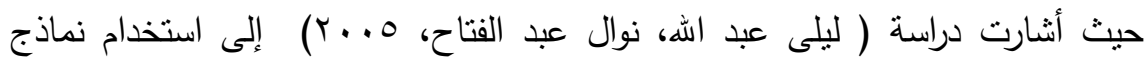
تربوية منل مهارات حل المشكلات يؤدي إلى تتمية الاستيعاب المفاهيمي، ويرى "مارزانو

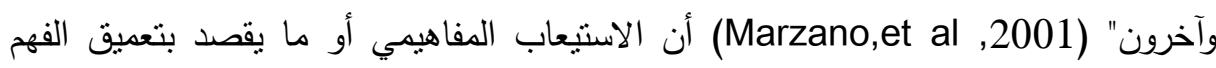

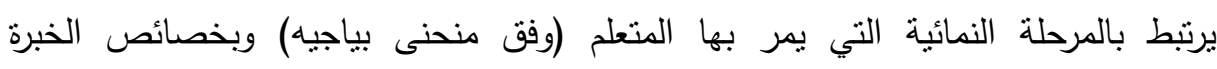

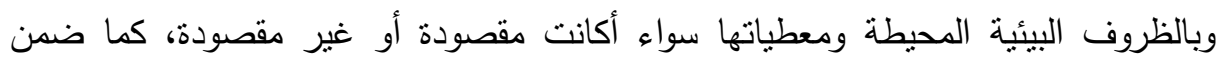
مارزانوا ثلاث عمليات فرعية في هذا المجال هي: ( تشكيل المفهوم، تشكيل المبدأ، والفهر مئه والاستيعاب).

فى ضوء ما سبق وحدود علم الباحثة لا توجد دراسة سابقة في التتمية المهنية لمعلمي

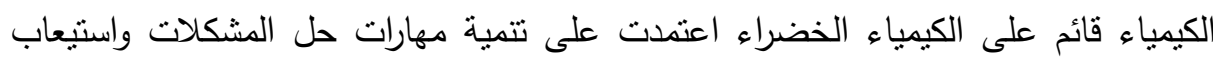

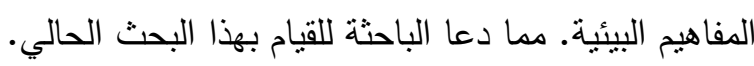

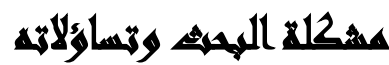

تم اجراء دراسة استطلاعية حول مبادئ الكيمباء الخضراء مناقثة مجموعة من معلمي

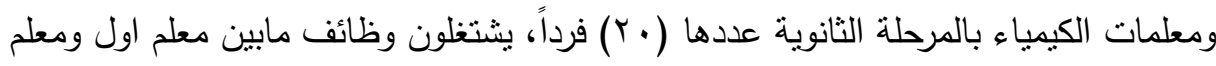
اول أ ومعلم خبير لمادة الكيمياءفي عدة ادارات بمحافظة القاهرة، وبالنسبة لمؤهلاتهم فإن معلم واحد فقط مؤهله ماجستير أما الباقي بكالوريوس علوم و بكالوريوس علورة علوم وتربية، ويوضح

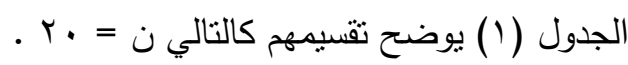


محمد سمير عبد المعز وآخرون

جدول( (1): الادارات وعدد سنوات الخبرة لمجموعة الدراسة الاستطلاعية

\begin{tabular}{|c|c|c|}
\hline عدد المعلمين & \multicolumn{2}{|c|}{ السمة } \\
\hline 7 & ادارة حلوان التعليمية & \multirow{4}{*}{ اسم الادارة } \\
\hline$\Gamma$ & ادارة المعصرة التعليمية & \\
\hline $\mathrm{V}$ & ادارة المعادي التعليمية & \\
\hline$\varepsilon$ & ادارة البساتين التعليمية & \\
\hline \multicolumn{3}{|c|}{ اجمالى عدد المعلمين = ، r معلم } \\
\hline 0 & معلم خبيز & \multirow{3}{*}{ الوظيفة } \\
\hline 1. & معلم أول آ & \\
\hline 0 & معلم أولَ & \\
\hline
\end{tabular}

أسفرت النتائج عن افتقار المعلم لمفاهيم الكيمياء الخضراء ولاتوجد لديهم خلفية عنها، ومن هنا ظهرت مشكلة البحث، ويرجع هذا لعدم مراعاة البرامج التدريبية للاحتياجات التدريبية للمعلمين.

ولاحظ الباحثون من خلال عملهم مع المعلمين كمدبين ومن خلال الدراسات السابقة ومنها دراسة (محمد ناصف، وآخرون ) والتي أوصت بضرورة عقد دورات تدريبية للمعلم بما يحقق له التتمية المهنية المستمرة بشرط ألا تقتصر عملية التدريب على المجال التربوي فقط، دونه

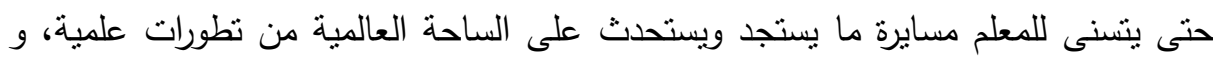
هدفت دراسة (2009, Marc, Gary) إلى دمج الكيمياء الخضراء في مناهج الكيمياء، وأن

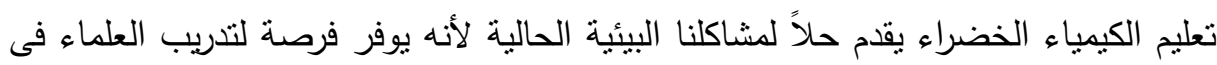

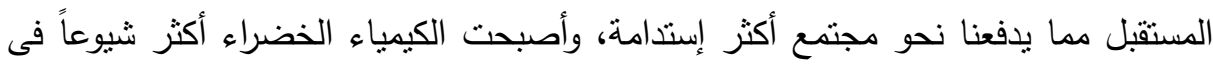
المناهج الدراسية وشهد أكبر قدر من التتفيذ فى مختبر الكيمياء العضوية.

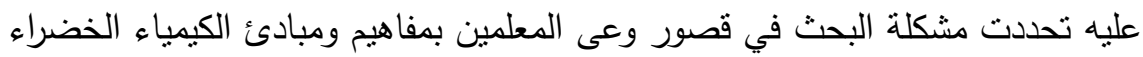
وقصور في استيعاب الدفاهيم البيئية لدى معلمي الكيمياء، وعدم تلقي معلمي الكيمياء تدريبات

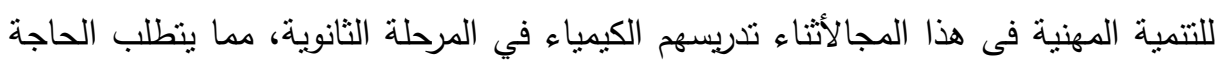
إلى برنامج تدريبي لهم يرتكز على الكيمياء الخضراء وقياس أثره في تتمية دهارات حل هل

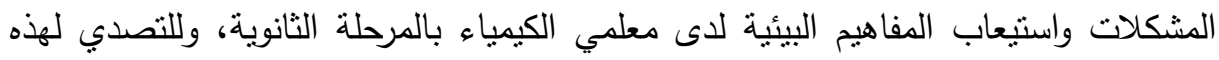

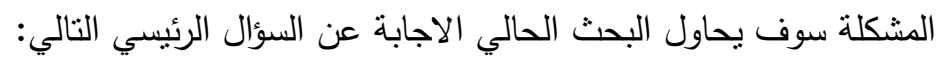

$$
\text { المجلد الأربعون، الجزء الأول، ديسمبر r. T }
$$


ما فاعلية برنامج تنمية مهنية لمعلمي الكيمياء بالمرحلة الثانوية فى ضوء الكيمياء الخضراء فى تنمية مهارات حل المشكلات واستيعاب المفاهيم البيئية؟ يتفرع عن هذا التساؤل الرئيسي الأسئلة الفرعية التالية:

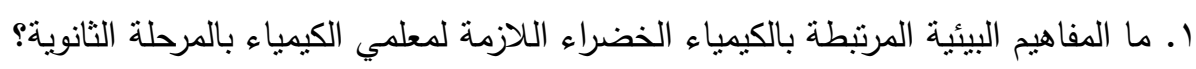

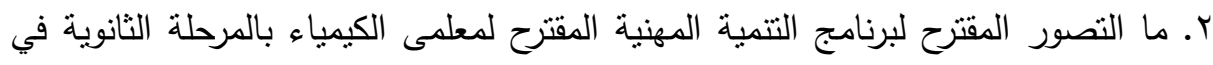
ضوء الكيمياء الخضراء؟ r. ما فاعلية البرنامج المقترح فى تتمية مهارات حل المشكلات لمعلمي الكيمياء بالمرحلة الثانويةج

ع. ما فاعلية البرنامج المقترح فى تتمية الدفاهيم البيئية لمعلمي الكيمياء بالمرحلة الثانوية؟

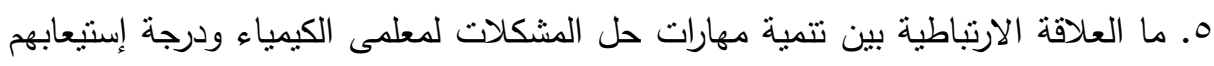

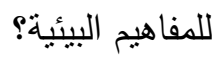

\section{أهما اهت المهمث}

ا. تتمية مهارات حل المشكلات في ضوء برنامج تدريبي " الكيمياء الخضراء" لمعلمي الكيمياء بالمرحلة الثنانوية. r. تتمية إستيعاب الدفاهيم البيئية في ضوء برنامج تدريبي" الكيمياء الخضراء" لمعلمي الكيمياء للمرحلة الثانوية.

\section{هروض المهنه}

انطلاقةا من التحلد السابق للمشكلة فإن البحث الحالي يحاول التحقق من صحة الفروض التالية: ا. يوجد فرق ذات دلالة إحصائياً عند مستوي دلالة (1.,.•) بين متوسطى درجات أداء

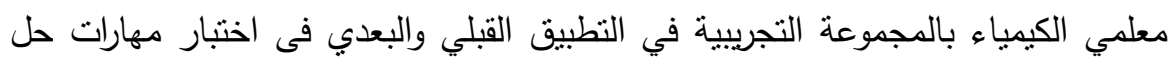


المشكلات (تحديد المشكلات البيئية - جمع المعلومات - فرض الفروض - اختبار صحة

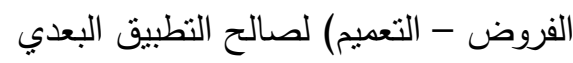
r. يوجد فرق دال إحصائياً عند مستوي دلالة (0. . •) بين متوسطى درجات معلمي الكيمياء

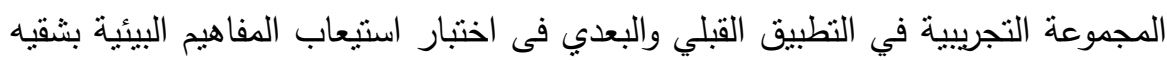
المعرفي(الثرح - التفسير - النطبيق- المنظور) والوجداني مقياس التعاطف ومعرفة الذات (التعاطف- معرفة الذات) لصالح التطبيق البعدي r. . يوجد علاقة ارتباطية موجبة بين مهارات حل المشكلات وتتمية استيعاب المفاهيم البيئية لاى معلمي الكيمياء بالمرحلة الثانوية

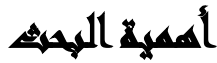

\section{قد تقيد نتائج البحث الحالي فيما يلى:}

1 ـ تقديم قائمة بالمفاهيم البيئية التي تساعد في الاثراء المعرفي للمعلم.

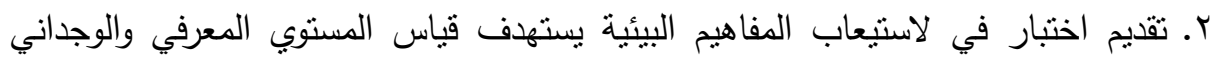
والسلوكي للمعلمين بالمرحلة الثانوية. r. تقديم اختبار مهارات حل المشكلات يمكن الاستفادة منه في أبحاث أخري. ء. تقديم برنامج تتمية مهنية يساعد مخططي ومطوري المناهج ومتخذي القرار في تفعيل دور معلمي الكيمياء للإهتمام بتطبيق مبادئ الكيمياء الخضراء أثناء التنريس.

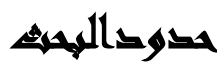

$$
\text { يقتصر البحث الحالي على: }
$$

• مجموعة من معلمي الكيمياء بالمرحلة الثانوية بإدارات ( المعادي، السيدة زينب، حلوان، لقدئ، المعصرة، البساتين، المقطم) وعددهم (•r معلم)- مديرية التربية والتعليم بالقاهرة.

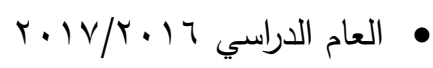

$$
\text { المجلد الأربعون، الجزء الأول، ديسمبر Y Y r. }
$$


• الدفاهيم البيئية (الكيمياء الخضراء - المواد البادئة الخضراء - العوامل المساعدة الخضراء-المذيبات الخضراء- الكواثف الخضراء - الطاقة المتجددة - منع التلوث- منع (الحوادث).

• مهارات حل المشكلات (تحديد المشكلة، جمع المعلومات،فرض الفروض،اختبار صحة الفروض،التعميم).

\section{منهمج المهيف}

المنهج شبه التجريبي: لقياس فاعلية البرنامج في تتمية مهارات حل المشكلات والاستيعاب المفاهيمي لمعلمي الكيمباء، حيث تم الاعتماد علي المنهج شبه التجريبي والتصميم التجريبي

للمجموعة الواحدة قبل وبعد تطبيق برنامج التتمية المهنية.

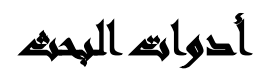

تمثلت أدوات البحث، التي قام الباحثون بإعدادها فيما يلي:

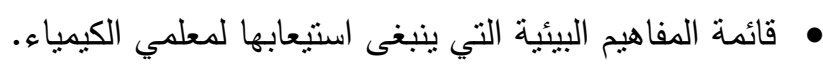
• اختبار مهارات حل المشكلات. • إختبار استيعاب المفاهيم البيئية.

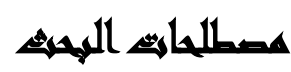

التنمية المهنية:ProfessionalDevelopment: تعرفها (سالي كمال، 17 • ب) بأنها"عملية مستمرة وشاملة للمعلم تستهدف زيادة معارفه وتطوير قدراته لرفع كفاعته المهنية وحل مشكلاته،وذلك لتحقيق نواتج تعلم ايجابية لطلابه،ويتم ذلك من خلال برامج تدريبية متنوعة.

وتعرف التنمية المهنية في هذا البحث: عملية تتضمن مجموعة من الإجراءات المخططة

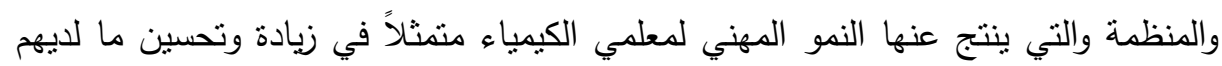


من معارف ومفاهيم ومهارات تتعلق بالبيئة ومسئولياتهم المهنية، وتطوير قدراته في حل المشكلات التي تواجهه.

الكيمياء الخضراء: Green Chemistry: هي الكيمياء صديقة البيئة والتي تعمل على عدم هدمها وفناء مواردها. وتهتم بالتخلص الآمن من النفايات عند المنبع، وتهت بالمناخ الصحي للعاملين في مجال الصناعات المختلفة، كما إنها تركز على توافر عوامل الأمان في أماكن الإنتاج للصناعات الكيميائية. (أحمد مجدي، 9 . . ب) وتعرف الكيمياء الخضراء في هذا البحث بأنها: استخدام التقنيات الكيميائية والطرق التي

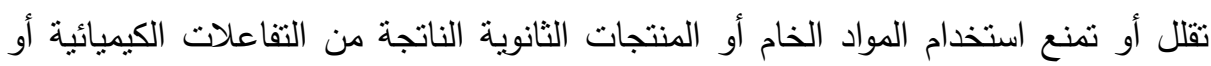
المذييات أو عوامل الحفز ...الخ في المعمل المدرسي والتي تكون خطرة على صحة المعلمين والطلاب.

مهارات حل المشكلات: problem solving skills: هي عطية سلوكية يحاول الفرد من خلالها تحديد واكتثاف وابتكار وسائل فاعلة للتعامل مع المشكلات التي يواجهها في

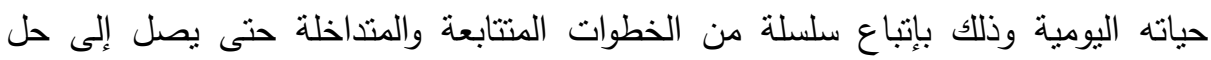

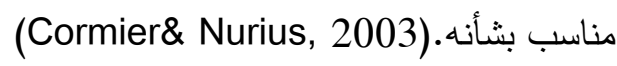
تعرف حل المشكلات في هذا البحث بأنها: نشاط تعليمي يواجه فيه معلم الكيمياء للمرحلة الثانوية " مشكلة " فيسعى إلى إيجاد حل لها، لذلك عليه أن يتبع بخطوات مرنبة تمانل خطوات الطريقة العلمية في البحث والتفكير ، ويصل منها إلى تعميم يعتبر حلاً لها. استيعاب المفاهيم البيئية: Understand the Environmental Concepts

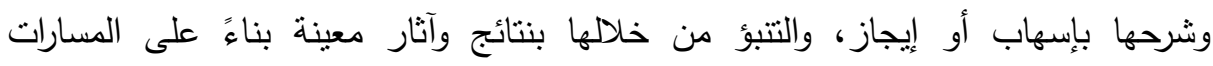

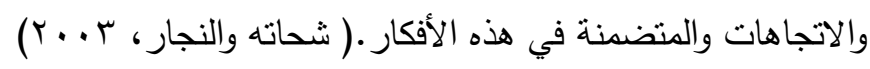
ويعرف في هذا البحث بأنها: قدرة معلم الكيمياء في المرحلة الثانوية على تعميق الفهم بتقديم معني للمفاهيم البيئية واستخدام انشطة تعليمية قائمة على التساؤلات، عن طريق تجريد الوقائع

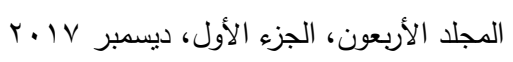


وذلك بتفسير بعض الوقائع والتوسع فيها لتعطي وضوحا في الافكار حول الكيمياء الخضراء ومبادئها.

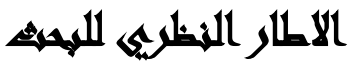

المحور الاول: التتمية المهنية لمعلم الكيمياء: المعلم عنصر بالغ الأهمية في العملية التعليمية والتربوية ومهما كانت السياسات التعليمية والتربوية على علم ودراية ووعي، وأهدافها نبيلة وخططها شاملة والوسائل والكتب رائعة، فإنها دون مشاركة فعالة من المعلم تصبح لا روح ولا حياة فيها، فالمعلم هو الذي ييث الروح في العملية التعليمية والتربوية ويزيد من فعاليتها ويثري ساحتها لذلك كان من الضروري الاهتمام ببرامج إعداد المعلمين في لهاه

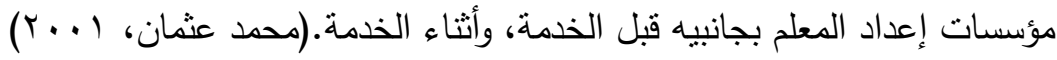

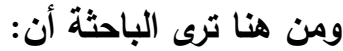
• التتمية المهنية للمعلم تتضمن أساليب ووسائل عدة منها الحلقات الدراسية، والبرامج التدريبية التي تقدم له أثناء الخدمة، وكذللك الأنشطة المتاحة له داخل وخارج المدرسة.

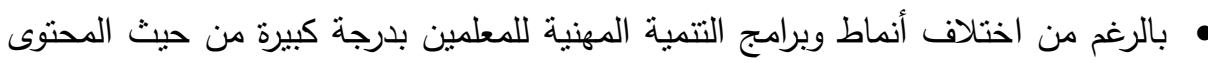
والثكل إلا أنها تتشتك من بعضها البعض في الهدف العام الذي تسعي إلى تحقيقه وهو

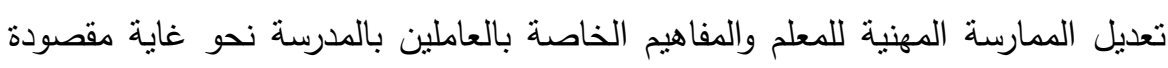
بقصد تحسين وتتمية تعليم الطالب. • التتمية المهنية للمعلم يجب أن تكون شاملة على كل جوانب النمو لدى المعلم فتشمل

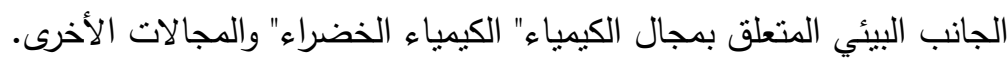
المحور الثاني: الكيمياء الخضراء: تهدف الكيمياء الخضراء إلي التوصل إلى طرق مبتكرة في الموارد المتجددة التي يمكن استخدامها لتحل محل غير المتجددة منها. والسعي إلي إلي تقليل الطلب على بعض الموارد غير المتجددة. إذا تهدف الكيمياء الخضراء من ذلك تقديم المواد التي تستخدم موارد أقل في عصرنا الحالي، لذا علينا أن نحاول تقليل كمية المواد الخام التي يتم تضمينها في إنتاج المنتج الكيميائي. كما يتم تطوير مواد جديدة تتفق مع معايير 
البيئة العالمية لضمان الملاءمة لغرض هذه المواد. فالكيمياء الخضراء نؤكد على إنتاج المواد الكيميائية المصممة للتحلل ببطء في البيئة دون أن يؤدي ذلك إلي اي اضطراب في دورات الطبيعية وأنظماتها.(Ankita Garg, 2012) وجوب دراسة الكيمياء الخضراء في المرحلة الثانوية للاسباب التالية: • توعية طلاب هذه المرحلة بمستقبل بيئته. • استخدام الطلاب مبادئ الكيمياء الخضراء اثثاء عمل التجارب المعطية ليكون تفكيره وسلوكه مرتبط بتحقيق مبادئها للحفاظ على البيئة. • عدم اشتمال المناهج المصرية على المشكلات البيئية وكيفية المشاركة في حلها، لذلك الكهاته يمكننا تعليم وتثقيف الاجيال المستقبلية من علماء ومهندسين ليكونوا على علم بهذه المشكلات.

$$
\text { مبادئ الكيمياء الخضراء }
$$
1 - منع التلوث: يفضل منع تكوين النفايات في المصدر بدلاً من معالجتها أو التخلص منهاء

$$
\text { بعد تكوينها. }
$$

Y- اقتصادالذرة: تصميم طرق التحضير بحيث تتدمج معظم المتفاعلات لتكون المنتج النهائي.

r- مخلفات كبيِيائبة أقل: تصميم طرق التصنيع بحيث يكون ناتج التفاعل لها أقل سميه.

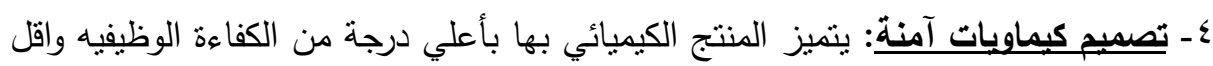

$$
\text { قدراً من السمية. }
$$

ه- تصميم مذيبات خضراء: يفضل إجراء التفاعلات بدون أو تقليل استخدام مواد اضافية

$$
\text { (المذيبات أو مواد الفصل) اذا لزم الأمر. }
$$

7- استخدام مواد بادئة متجددة : يجب أن تكون الخامات التي نستخدم منها المواد البادئة

$$
\text { مواد متجدده بدلا من استتزاف الخامات غير المتجدده. }
$$

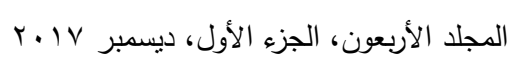


V- عوامل مساعدة بـيلة: انتقاء الكواثف المحفزه المستخدمة في التفاعلات الكيميائية لا تؤثز سلبا على صحة الانسان والبيئة، أفضل من كواثف متكافئة التركيب ذات التأثثر السئ.

ᄉ- تقليل المشتقات الكيمبيائبة: يجب ما أمكن تجنب العمليات الكيميائية والفيزيائية غير الضرورية مثل اشتقاق مجموعات بعينها أو إجراء تعديلات مؤقته في الجزئيات. 9- تصميم طاقة خضراء: يجب الأخذ في الاعتبار اختبار الطاقة المتجدة بدلا عن الطاقة غير المتجددة مع دراسةمدى احتياج الطاقة عامة نظراً لتكلفتها وتأثيرها البيئي.

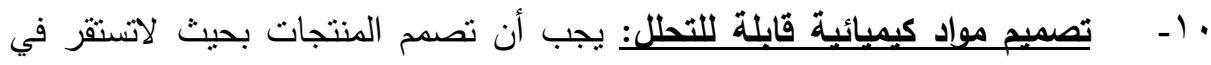
البيئة بعد اداء وظيفتها ويجب أن تكون قابله للتحلل في البيئه إلى مواد بسيطة غير ضاره بها.

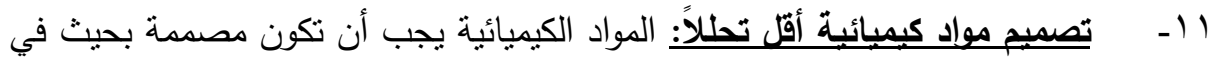

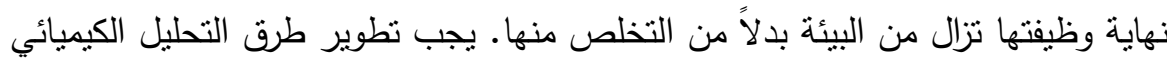
لتواكب سير التفاعل لحظيا بحيث نراقب وتسيطر على التفاعل قبل تكوين اي مواد خطره.

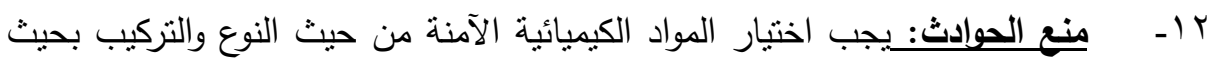

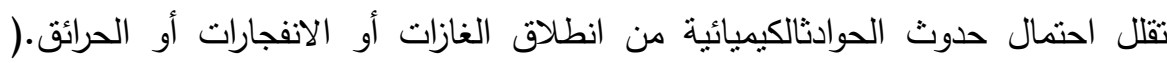
(Y...V، محمد سمبر (T) المحور الثالث: مهارات حل المشكلات: هي مستوى رفيعٍ من التفكير، يكمن في نوليد

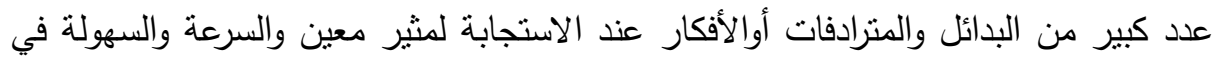
توليدها، أو توليد أفكار غير متوقعة، وتوجيه مسار التفكير حسب تغيير المثير أومتطلبات

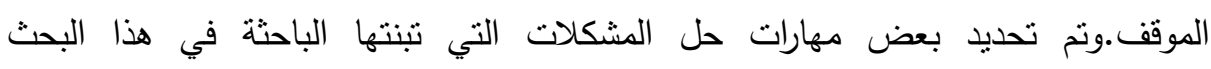
لاستخدامها في البرنامج التدريبي لمعلمي الكيمياء في ضوء الكيمياء الخضراء، وهي كما يلي: 
ع. اختبار صحة الفروض.

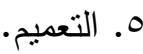

المحور الرابع :استيعاب المفاهيم البيئية: هو القدرة على إدراك المعاني من خلال ترجمتها من صورة إلى أخرى، وتقسيرها وشرحها بإسهاب أو إيجاز ، والتتبؤ من خلالها بنتائج وآثار معينة بناء على المسارات والاتجاهات المتضمنة في هذه الأفكار .

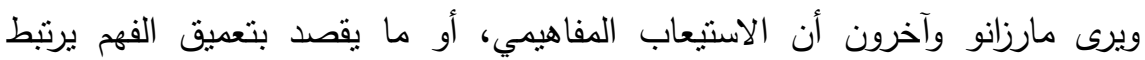

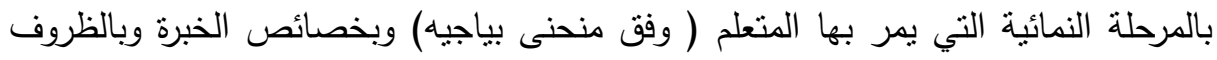
البيئية المحيطة ومعطياتها سواء أكانت مقصودة أو غبر مقصودة، كما ضمن مارزانو ثنلاث عمليات فرعية في المجال هي: ( تشكيل المفهوم، وتثكيل المبدأ، والفهم والاستيعاب). ومن هنا نصل إلى عوامل تحقيق الاستيعاب المفاهيمي: 1-الثرح: Explanatio: قدرة المتعلم على تقديم أوصاف متقنه للظواهر والأحداث والأفكار وإيجاد جوهر الموضوع واستخراج الأفكار الرئيسة .ويستطيع المتعلم هنا أن يبسط المفهوم أو الحدث ويقدم المعنى بلغته الخاصة، فهو لا يردد تعريفا لمصطلح ورد في الكتاب المدرسي.

r-التفسير: Interpretation: قدرة المتعلم على الوصف ذي المعنى لما بتعلمه من موضوعات وإجراء الاستخلالات واستخلاص الاسنتتاجات .تتقارب القدرة على الثرح والقدرة على التفسير،ولكنهما عمليتان مختلفتانهبينما يركز الثرح على توضيح المعنى ينتقل الهدف هنا إلى توضيح أهية هذا الموضوع. r- التطبيقA Application: قدرة المتعلم على استخدام التجريدات من المفاهيم والقوانين والحقائق والنظريات التى سبق أن تعلمها في مواقف جديدة وسياقات مختلفة .وتعنى ببساطة تمكن المتعلم من استعمال ما لديه من معرفة حول موضوع معين بكفاءة،

$$
\text { وبخاصة في مواقف جديدة ومنتوعة. }
$$

צ-المنظور :Perspective: قدرة المتعلم على تكوين وجهات نظر ناقدة ومستبصرة لما

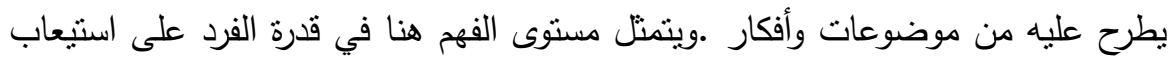

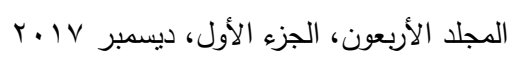


فكرة أن هنالك وجهات نظر مختلفة حول الأشياء والموضوعات والأفكار : ويدرك أن هنالك أكثر من إجابة لكل سؤال، وهناك أكثر من حل لكل مشكلة، وأن من حقه أن تكون لـ له وجهة نظر . ه-التعاطف:Empathy: قدرة المتعلم على الإدرالك بحساسية وأن يضع نفسه مكان الآخر لإدراك العالم من وجهة نظر هذا الآخر .ويركز الفهم في هذا المستوى على الآخرين.

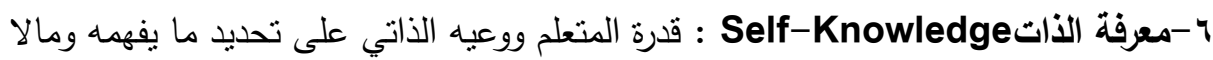
يفههد من موضوعات وأفكار، وكيف تؤدى أنماطه فى التفكير وأفعاله إلى الفهم المسنتير أو إلى الفهم المتحيز •يصل الفرد في هذا الوجه لمستوى الحكمة، فيعرف قدراته وعيوبه وتحيزاته في فهم أو تفسير أي موضوع.

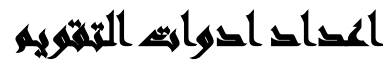

تم إعداد المواد التدريبية ( دليل المدرب - أوراق العمل - شرائح العرض التقديمي دليل المتدرب) وفق الخطوات التالية:

ا.إعداد دليل المدرب: اشتمل دليل المدرب لبرنامج الكيمياء الخضراء على العناصر

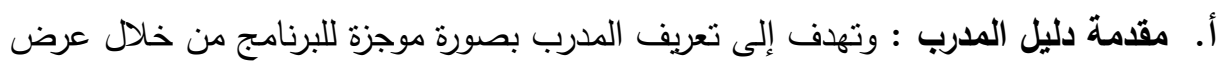
لبرنامج الكيمياء الخضراء المقترح وأهدافه وطرق التدريب المستخدمة بالبرنامج، الأنشطة التي يقوم بها المتدربون، وأدوات ووسائل، وأجهزة تتفيذ البرنامج بصفة عامة، وأساليب

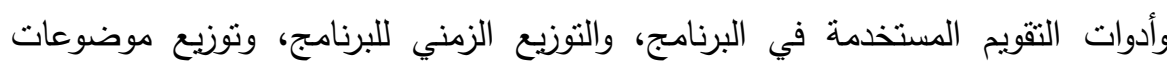

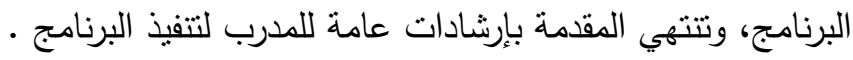
ب. جلسات التدريب: وتشمل كل جلسة تدريبية على: م رقم اليوم التنديبي، ورقم كل جلسة. م عناصر الجلسة: وتحدد ما يجب أن يتحقق لدى المتدرب بعد الانتهاء من الجلسة التدريبية. 
م الأدوات والوسائل والأجهزة اللازمة لتتفيذ الجلسة. م مرق ووسائل التدريب. م إجراءات قبل نتفيذ الجلسة.

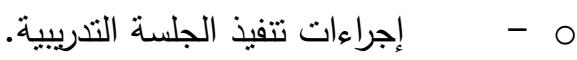

r.إعداد دليل المتدرب و أورلق العمل: اشتمل دليل المتدرب و أوراق العمل لبرنامج الكيمياء الخضراء على العناصر التالية:

أ. استمارة بيانات المتدرب : لتحديد اسمه واسم المدرسة واسم الإدارة، وعدد سنوات الخبرة، والمؤهل الدراسي، وتاريخ الحصول عليه.

ب. مقدمة الاليل: وتهدف إلى تعريف المتدرب بالبرنامج وأهدافه العامة والأنشطة المطلوبة منه داخل التدريب وأساليب وأدوات البرنامج، والتوزيع الزمني للبرنامج، وتتتهي المقدمة بإرشادات عامة للمتدرب لتتفيذ البرنامج. ج. أورلق العمل لكل جلسة تدريبية ملحقة بأهداف الجلسة: وقد روعي في إعداد أوراق

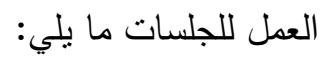
- أن يكون هناك عنوان لكل ورقة عمل لحث المتدرب على التفكير ولجذب انتباهه. - وجود فراغات مناسبة للكتابة. - وبالنسبة للمقالات التي يتم استخدامها في الجلسات، فقد روعي أن تكون هذه المقالات مرتبطة بالمفاهيم الموجودة بالجلسة التدريبية.

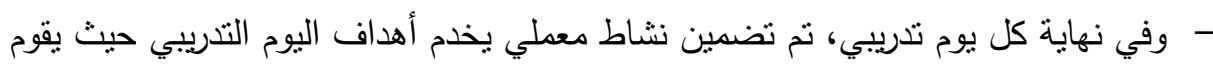
المتدرب بعمل هذه التجارب بنفسه. ب- شرائح العروض التقديمية (power point) المصاحبة للبرنامج): يتضمن ملف البوربوينت للبرنامج عدد (17 (1) شريحة مقدمة وفقا لجلسات البرنامج التدريبي، وتتضمن هذه الثرائح عرضاً لأهداف الأيام التدريبية، وشرحا للموضوعات العلمية المتضمنة بالبرنامج التدريبي، وهذا الثرح مصحوبا برسومات توضيحية أو بصور أو بلقطات فيديو لتوضيح

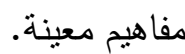


ع .تحديد صلاحية المواد التدريبية: بعد الانتهاء من إعداد دليل المدرب وأوراق العمل الخاصة بالبرنامج، نم عرض دليل المدرب وأوراق العمل وشرائح العرض التقديمي على بلى التهن مجموعة من خبراء المناهج وطرق التدريس وأساتذة الكيمياء للتعرف على آرائهم من حيث مدى : • • دقة ووضوح الأهداف الخاصة بكل جلسة.

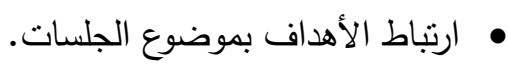
• • • • مدى ملائمة أوراق العمل وشرائح العرض التقديمي لموضوع كل جلسة.

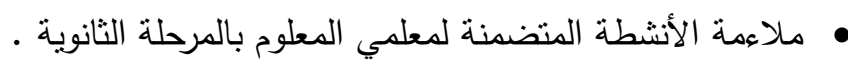

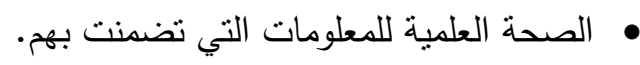
وقد تم تعديل المدرب وأوراق العمل في ضوء آراء السادة المحكمين وبذلك أصبح دليل الددرب وأوراق العملفي صورتها النهائية وصالحين للنطبيق.

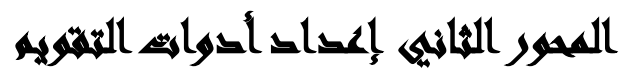

أولاً: إعداد اختبار مهارات حل المشكلات: تم تصميم اختبار لقياس قدرة معلي المرحلة الثانوية على حل المشكلات، ولقد مرت عملية بناء الاختبار بالخطوات التالية:

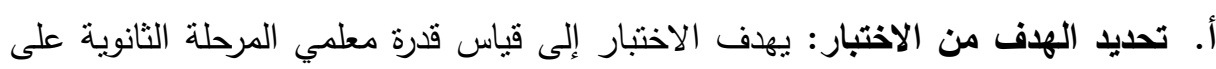

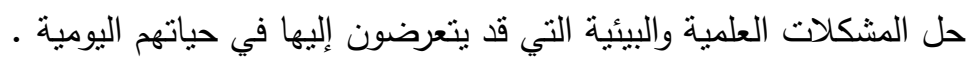

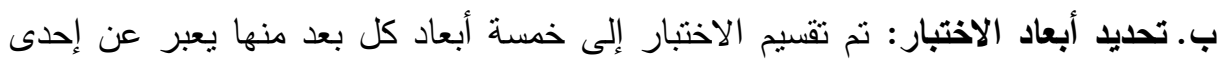

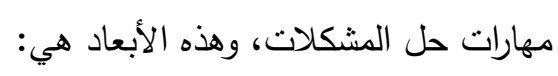

ا . تحدبد المشكلة: ويتضمن هذا البعد مجموعة عبارات يعبر كل منها عن إحدى المشكلات،

$$
\text { وعلى المعلم تحديد هذه المشكلة بدقة . }
$$

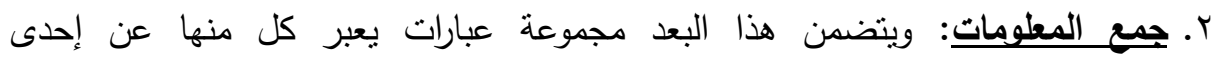
المشكلات، وعلى المعلم اختيار أفضل الطرق المناسبة للحصول على المعلومات التي لئي

$$
\text { تساعد في حل المشكلة. }
$$


r. فرض الفروض: ويتضمن هذا البعد مجموعة عباراتيعبر كل منها عن إحدى المشكلات يتبعها مجموعة فروض وعلى المتعلم استيعاد الفروض الخطأ.

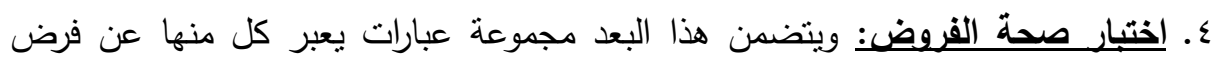
ووسائل اختبار صحة الفرض وعلى المعلم اختيار أفضل وسيلة لاختبار صحة هذا هئل الفرض. ๑. التعبم: ويتضمن هذا البعد مجموعة عبارات يمكن من خلالها استخلاص بعض النتائج الثناملة والتي يمكن تعميمها على مواقف أخرى مشابهة. ج. إعداد الاختبار في صورته الأولية: تكون الاختبار في صورته الأولية من (Y0) مفردة،

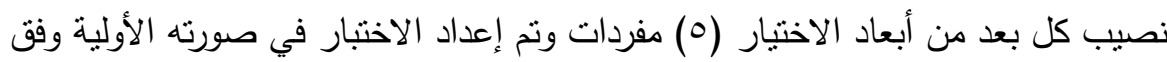
ما يلي: ا. صبياغة تعليمات الاختبار : وضعت تعليمات الاختبار في الصفحة الأولى من كراسة

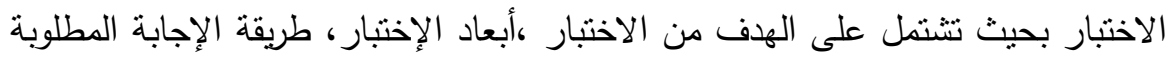
بالإضافة إلى ذلك نم وضع مثال مجاب عنه في بداية كل بعد من أبعاد الاختبار .

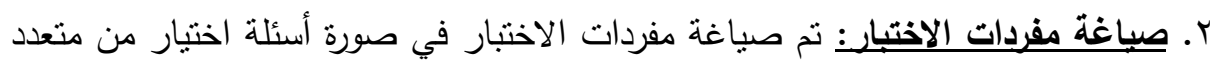
وتتكون كل مفردة من جزئين : أ. مقدمة السؤلِ: تتضدن مقدمة السؤال موقف معين يحتوي على كل البيانات والمعلومات

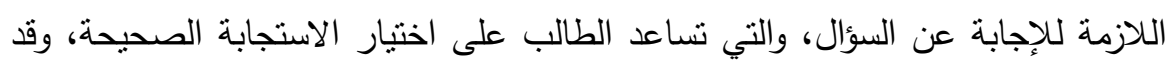
روعي في صياغة مقدمة السؤال الا ترتبط المقدمة بمحتوى برنامج الكيمياء الخضراء الذباء الذي الذيه

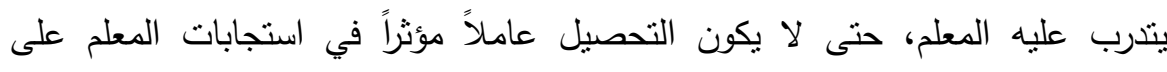

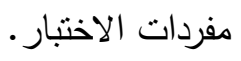

ب.بدائل الإجابة: تلي مقدمة كل سؤال اربعة بدائل، ويوجد بديل واحد فقط صحيح، وقد روعي في صياغة البدائل تجانس الاستجابات مع بعضها ومع مقدمة السؤال.

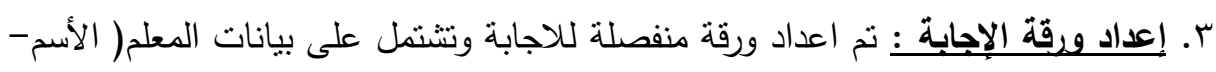
المدرسة - الادارة- التاريخ) ونم ترقيمها من (1) إلى (Y0) وأمام كل رقم ربع خانات

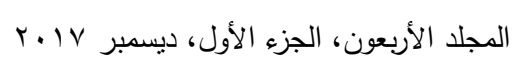


فارغة ( أ، ب،ج×د) وعلى الطالب وضع علامة (ل) في الخانة التي تعبر عن البديل

ع. إعداد مفتاح التصحبح : نم اعداد مفتاحا لتصحيح الاختبار .

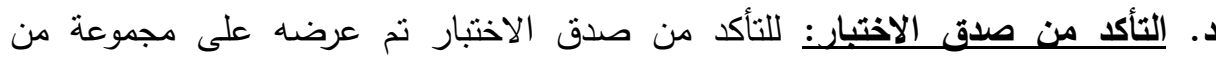
المتخصصين في مجال المناهج وطرق التدريس وكذلك المتخصصين في علم الكيمياء

$$
\text { وذلك لإبداء الرأي فيه من حيث: }
$$

ا ـ شمول الاختبار لكافة المهارات الفرعية لحل المشكلات.

r. مناسبة كل مفردة للمهارات الفرعية التي تقبسها. r. مناسبة كل مفردة لطبيعة معلمي المرحلة الثانوية والكيمياء الخضراء. ع. الصحة العلمية واللغوية. ه. مقترحات أخرى ( اضافة أو حذف). مدى صلاحية الاختبار للتطبيق:.وقد أجرت الباحثة التعديلات التي أقرها السادة المحكمون،

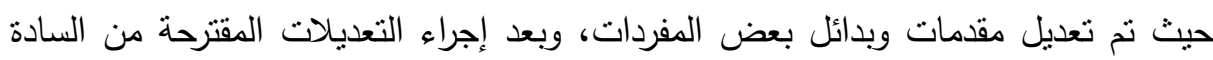
المحكمين، أصبح الاختبار مكوناً من (ب0) مفردة، وبالتالي تكون الدرجة الكلية للاختبار هץ درجة .

هـ. التجرية الاستطلاعية للاختبار: تهدف التجربة الأسنطلاعية للاختبار إلى حساب ثبات الاختبار، والزمن الملائم للإجابة عن أسئلته؛ ولتحقيق ذلك نم تطبيق الاختبار على الإسئ

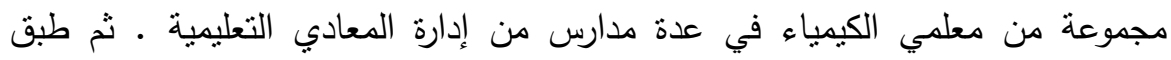

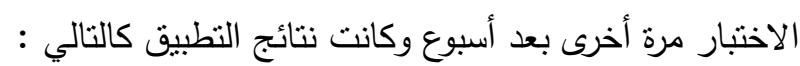
حساب ثبات الاختبار: تم حساب معامل ثبات الاختبار بطريقة إعادة النطبيق على عينة

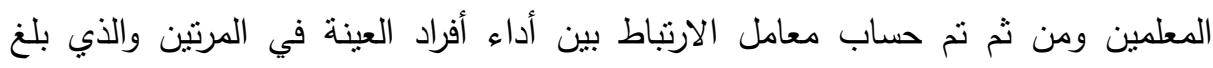

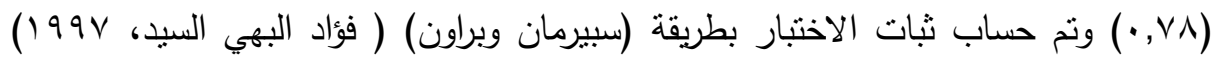
وقد بلغ (AVT, · ) وهذا يشير إلى ارتفاع معامل ثبات الاختبار . 
تحديد زمن الاختبار: نم حساب زمن الاختبار عن طريق حساب المتوسط بين الزمن الذي

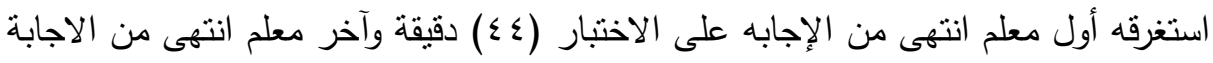

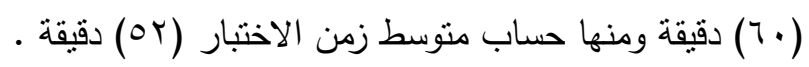

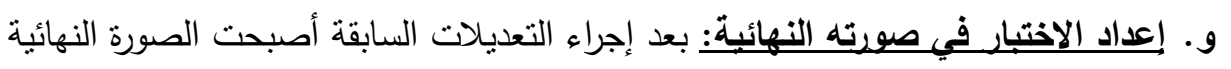

$$
\text { للاختبار مكونة من (Y0) مفردة، كما يوضحه الجدول (Y): }
$$

\begin{tabular}{|c|c|c|}
\hline ارقام المفردات & عدد المفردات & ابعاد اختبار مهارات حل المشكلات \\
\hline من إلىي & 0 & تحديد المشكلة \\
\hline من 7 إلى & 0 & جمع المعلومات \\
\hline من 11 إلى 10 & 0 & فرض الفروض \\
\hline من 7 إإلى .r & 0 & اختبار صحة الفرض \\
\hline من إY إلى Yo & 0 & التعميح \\
\hline من ا إلى & ro & المجموع \\
\hline
\end{tabular}

جدول(ץ): توزيع مفردات اختبار مهارات حل المشكلات على أبعادة

$$
\text { ثانياً :إعداد اختبار الاستيعاب المفاهيمي: }
$$

أ. اختبار استيعاب المفاهيم البيئية: المعرفي:تم تصميم اختبار لقياس قدرة معلمي المرحلة الثانوية على استيعاب المفاهيم البيئية في ضوء الكيمياء الخضراء، ولقد مرت عملية بناء

$$
\text { الاختبار بالخطوات التالية: }
$$

ا. تحبد الهيف من الاختبار:هدف هذا الاختبار إلى قياس الاستيعاب المفاهيمي لدى معلمي الكيمياء بالمرحلة الثانوية في المفاهيم البيئية المتضمنة في برنامج "التتمية المهنية الهين

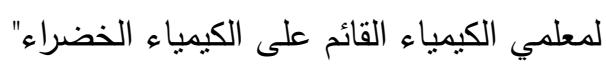
r. تحدب أبعاد الاختبار:تم تقسيم الاختبار إلى (اختبار استيعاب المفاهيم البيئية المعرفي

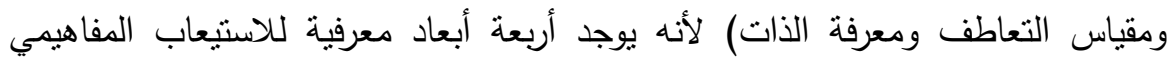

$$
\begin{aligned}
& \text { وبعدين وجدانيين وهي: }
\end{aligned}
$$

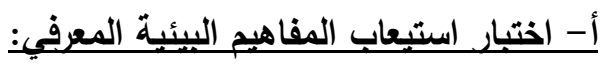

$$
\begin{aligned}
& \text { ينقسم هذا الاختبار إلى أربعة أبعاد معرفية وهي : }
\end{aligned}
$$


() الشرح: ويتضن هذا البعد قدرة المعلم على تقديم أوصاف متقنة للظواهر والأحداث والأفكار وإيجاد جوهر الموضوع واستخراج الأفكار الرئيسة فيه والتعبير عنها بإيجاز

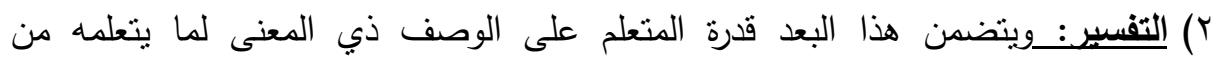
موضوعات وإجراء الاستدلالات واستخلاص الاسنتتاجات.

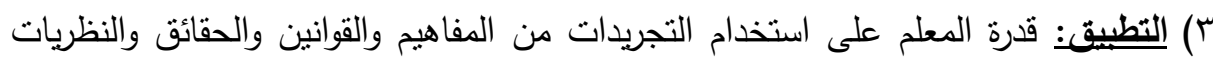
التي سبق أن تعلمها في مواقف جديدة وسياقات مختلفة.

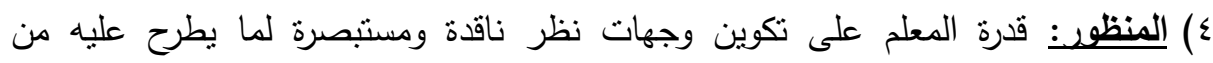

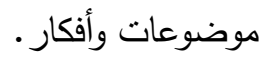

\section{إعداد الاختبار في صورته الأولية وفق الخطوات التالية:}

ا ـ تحديد مفردات الأختبار وصياغتها: صيغت مفردات الاختبار من نوع أسئلة الاختيار من

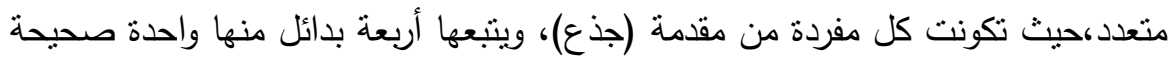

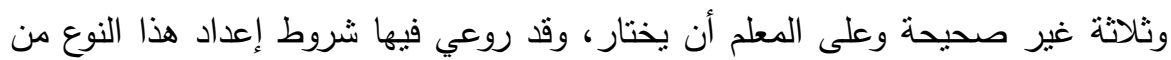

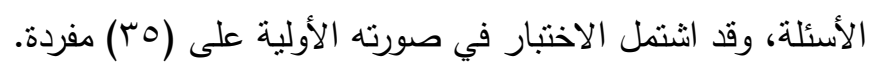

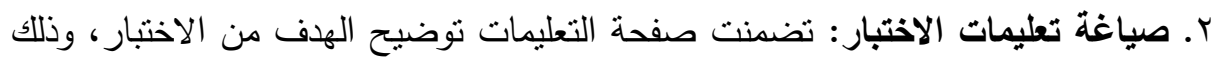
بالإضافة إلى مجموعة من التعليمات التي تنين للطالب كيفية الإجابة عن مفردات

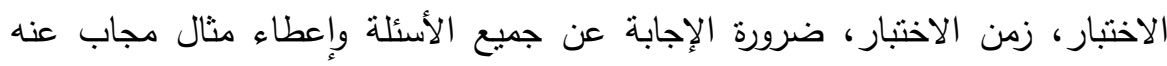

$$
\text { لتوضيح كيفية الإجابة عن الأسئلة. }
$$

r. إعداد ورقة الإجابة ونظام تقدير الارجات: صممت ورقة إجابة منفصلة عن كراسة الإسطة الأسئلة، ووضع تقدير الدرجات في هذا الاختبار بحيث تعطى درجة واحدة فقط في حالة الاجة الإجابة الصحيحة، وصفر في حالة الإجابة غير الصحيحة.

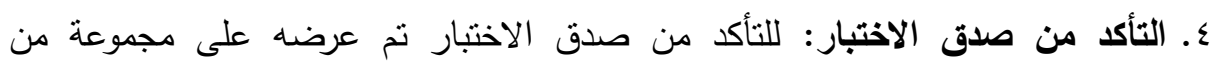
المتخصصين في مجال المناهج وطرق التدريس وكذلك المتخصصين في العلوم وذلك

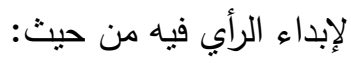




$$
\begin{aligned}
& \text { - شمول الاختبار لأبعاد الاستيعاب الدفاهيمي التي تم تحديدها. } \\
& \text { - مناسبة كل مفردة للبعد الذي تقيسه. } \\
& \text { - - مناسبة كل مفردة لطبيعة معلمي الكيمياء بالمرحلة الثانوية. } \\
& \text { - - الصحة العلمية واللغوية. } \\
& \text { - - أية مقترحات أخرى (إضافة، حذف). }
\end{aligned}
$$

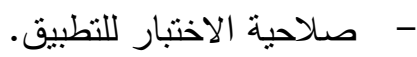

وبعد إجراء التعديلات المقترحة من السادة المحكمين، أصبح الاختبار من (ب0) مفردة

وبالتالي تكون الدرجة الكلية للاختبار (ب0) درجة حيث تم تحديد درجة واحدة لكل مفردة.

1-التجربة الاستطلاعية للاختبار:تهدف التجربة الاستطلاعية للاختبار إلى حساب ثبات

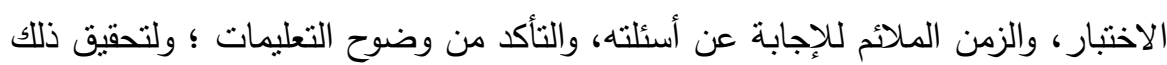

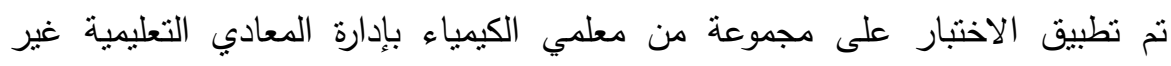
مجموعة البحث ثم طبق الاختبار مرة أخرى بعد أسبوعين، وقد كانت نتائج التجربة

كالتالي:

أ- حساب ثبات الاختبار : نم حساب ثبات الاختبار بطريقة إعادة التطبيق على عينة الطلاب

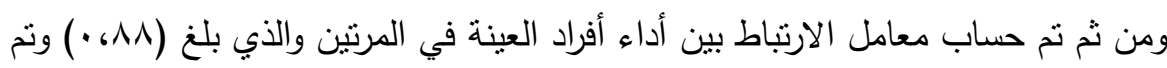

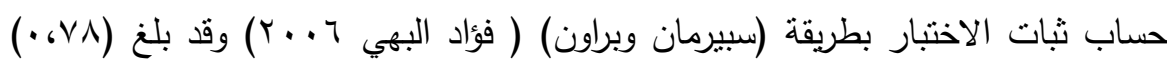

$$
\text { وهذا يشير إلى ارتفاع معامل الثبات. }
$$

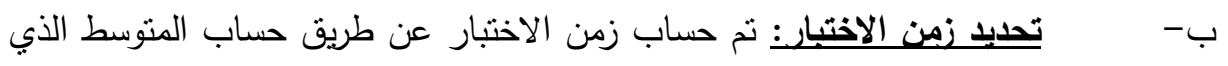

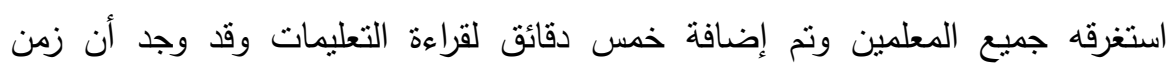

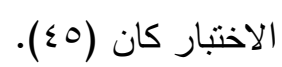

r- إعداد الاختبار في صورته النهائية: بعد إجراء السابقة أصبحت الصورة النهائية للاختبار

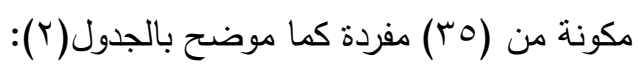

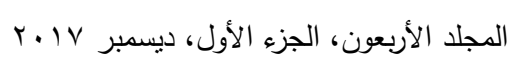


جدول(Y): نوزيع مفردات اختبار الاستيعاب المفاهيمي المعرفي على ابعاده

\begin{tabular}{|c|c|c|}
\hline ارقام المفردات & عدد المفردات & ابعاد اختبار الاستتِعاب المفاهيمى \\
\hline من ا إلى • & 1. & الثرح \\
\hline من Iا إلى ·r & $1 \cdot$ & التقسير \\
\hline من اY إلى YA & $\Lambda$ & التطبيق \\
\hline من qج إلى هب & $\mathrm{V}$ & المنظور \\
\hline من ا إلى مب با & ro & المجموع \\
\hline
\end{tabular}

ثالثاً: مقياس التعاطف ومعرفة الأتات ينقسم هذا المقياس إلى بعدين وهما: 1-التعاطف: وهي قدرة المعلم على الإدراك بحساسية وأن بضع نفسه مكان الآخر لإدراك العالم من وجهة نظر هذا الآخر • ويركز الفهم في هذا المستوى على الآخرين.

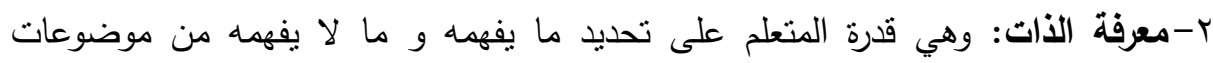

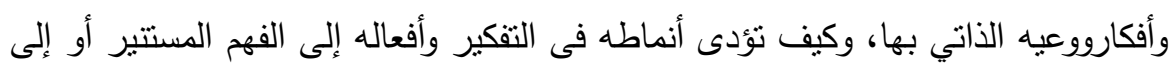
الفهم المتحيز حتى يصل الفرد في هذا الوجه لمستوى الحكمة. إعداد المقياس في صورته الأولية: - تحبد مفردات المقياس: وصياغتها:يكون المقياس في صورته الأولية من (• (؟) مفردة، نصيب كل بعد من البعدين (•r) مفردة، ويتكون المقياس من مجموعة من العبارات كما في مقياس ليكرد الثلاتي (أوافق- محايد- غير موافق) ويمكن للمعلم اختبار الإجابة المناسبة لآرائه . - صباغة تعليمات المقياس: تضمنت صفحة التعليمات نوضيح الهدف من المقياس، بالإضافة إلى مجموعة من التعليمات التي تبين للمعلم كيفية الإجابة عن مفردات المقياس، زمن المقياس، ضرورة الإجابة عن جميع الأسئلة وإعطاء مثال مجاب عنه لتوضيح كيفية

$$
\text { الإجابة عن الأسئلة. }
$$

- التأكد من صدق المقياس:_للتأكد من صدق المقياس نم عرض على مجموعة من الإسل

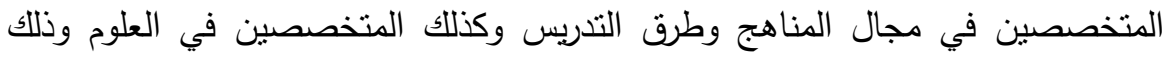


لإبداء الرأي، وبعد إجراء التعديلات المقترحة من السادة المحكمين،أصبح المقياس من

$$
\text { ( • • مفردة وبالتالي تكون الدرجة للمقياس ( • ع) درجة. }
$$

- التجرية الاستطلاعية المقياس: تهدف التجربة الاستطلاعية للمقياس إلى حساب ثبات درجهات

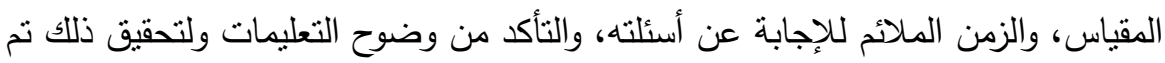

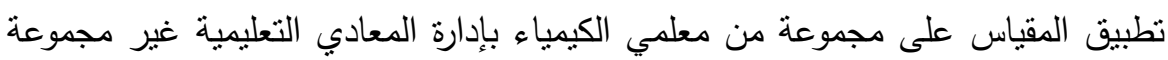
البحث ثم طبق المقياس مرة أخرى بعد اسبوعين، وقد كانت نتائج التجربة كالتالي:

أ- حساب ثبات المقياس:تم حساب ثبات المقياس بطريقة إعادة التطبيق على عينة المعلمين

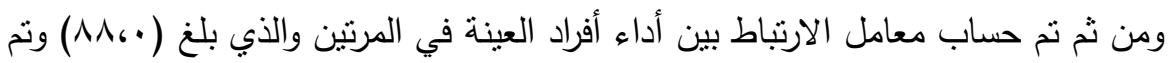

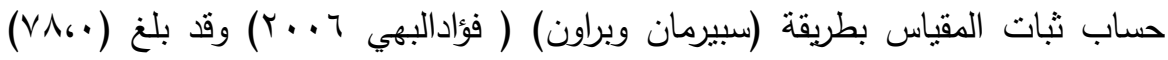
وهذا يشير إلى ارتقاع معامل الثبات.

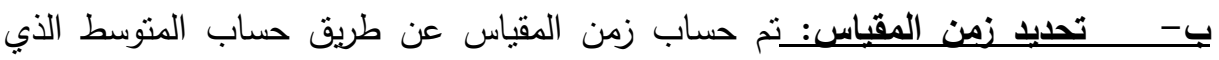

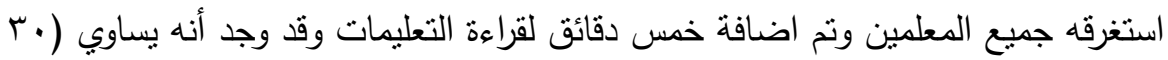

- إعداد المقياس في صورته النهائبة: بعد إجراء التعديلات السابقة أصبحت الصورة

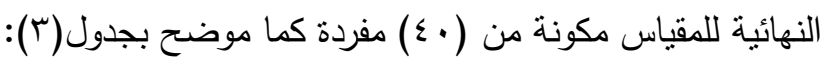

جدول(r): توزيع مفردات مقياس التعاطف ومعرفة الذات على ابعاده

\begin{tabular}{|c|c|c|}
\hline ارقام المفردات & عدد المفردات & ابعاد المقياس \\
\hline من ا إلى . & $r$. & التعاطف \\
\hline من إللى •r & $r \cdot$ & معرفة الذات \\
\hline من ا إلى .ع & To & المجموع \\
\hline
\end{tabular}

المحور الثالث: التجربية الميدانية

1. التصميم التجريبي: اختار البحث التصميم التجريبي من نوع المجموعة الواحدة مع اختبار قبلي - بعدي، نظرًا لأهمية هذا النوع من التصميمات التجريبية حيث تقوم الباحثة بملاحظة أداء المفحوصين قبل وبعد تطبيق المتغير التجريبي ( البرنامج المقترح " الكيمياء الخضراء")، ويقيس التغير الذي يحدث لكي يحدد تأثنر المتغير المستقل على المتغيرات التابعة، وكذللك للحصول على مقدار التغير الذي حدث نتيجة التعرض للتنغير التجريبي.

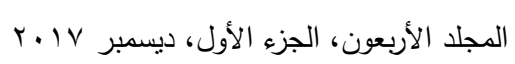


r. متغيرات الدراسة: حيث إن الدراسة الحالية تهدف إلى تتمية مهارات حل المشكلات والستيعاب المفاهيم البيئية من خلال البرنامج المقترح " الكيمياء الخضراء" للتنمية المهنية

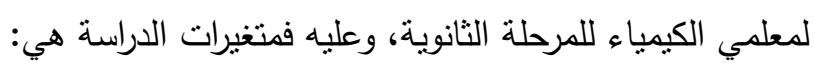

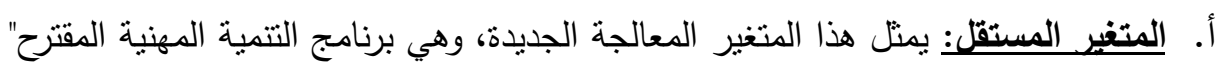
الكيمياء الخضراء". ب. المتغيرات التابعة:وهذه المتغيرات هي تتمية مهارات حل المشكلات واستيعاب المفاهيم البيئية لدى معلمي الكيمياء بالمرحلة الثانوية.

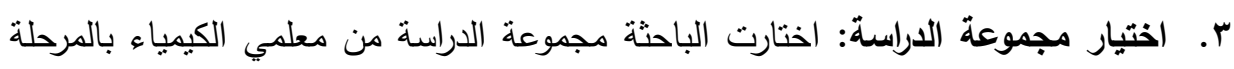

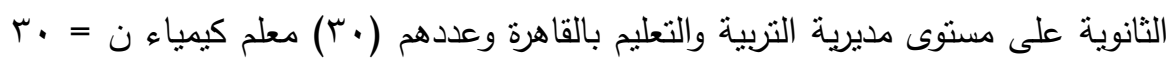
معلم ؛. التطبيق القبلي لأداتي الدراسة: قامت الباحثة بتطبيق أدوات التقويم قبلياً على مجموعة الدراسة والمتنظة في: اختبار مهارات حل المشكلات ؛ اختبار الاستيعاب المفاهيم البيئية

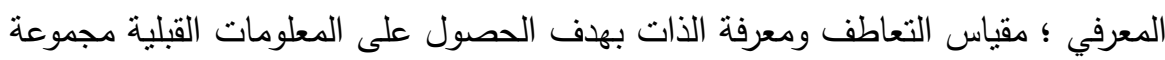
الدراسة .

ع -تقديم برنامج " الكيمياء الخضراء" لمجموعة الدراسة: بعد الانتهاء من عملية التطبيق القبلي للادوات بدأت عملية التدريب لمجموعة الدراسة من معلمي الكيمباء يوم الاحد

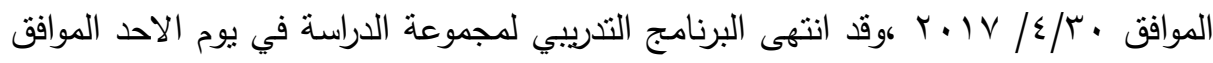

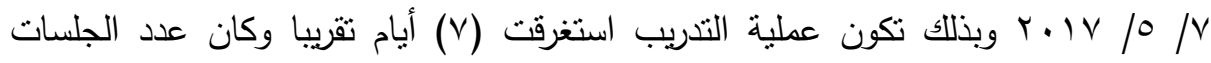
( ) ( ) ( ) جلسة تدريبية. ه-التطبيق البعدي لأداتي الدراسة: بعد الانتهاء من البرنامج التدريبي للجموعة الدراسة

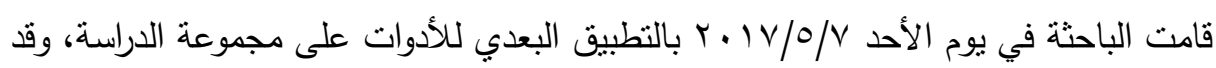
انتهى التطبيق البعدي للادوات في يوم الأحد. צ-تصحيح أدوات الدراسة ورصد النتائج: تم تصحيح أدوات الدراسة ورصد النتائج ثم معالجتها إحصائياً تمهيداً لتفسيرها وتقديم المقترحات والتوصيات بشأنها. وللتأكد من فاعلية 370

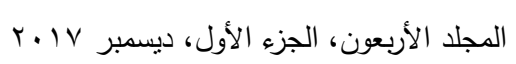


برنامج التتمية المهنية لمعلمي الكيمياء بالمرحلة الثانوية القائم على الكيمياء الخضراء تم حساب معدل الكسب لبلاك:

\begin{tabular}{|c|c|c|c|}
\hline ص - س & \multirow{2}{*}{+} & ص - س & \multirow{2}{*}{ عدل = } \\
\hline د & & د - س & \\
\hline
\end{tabular}

ص : منوسط درجات المعلمين بعد دراستهم البرنامج التدريبي (التطبيق البعدى). س : منوسط درجات المعلميين قبل دراستهم للمنهج (التطبيق القبلى).

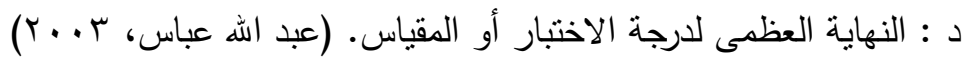

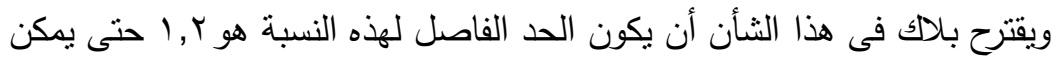
اعتبار فاعلية المنهج مقبولا.

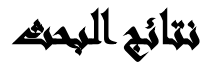

توصل البحث إلى النتائج التالية: جدول(؟): قيمة "ت" لدلالة الفروق بين درجات المجموعة التجريبية

\begin{tabular}{|c|c|c|c|c|c|c|c|}
\hline \multirow{2}{*}{ الدستوية } & \multirow{2}{*}{ قيم ت } & \multicolumn{2}{|c|}{ الانحراف } & \multicolumn{2}{|c|}{ المتوسط } & \multirow{2}{*}{ الالكية } & \multirow{2}{*}{ المستوى } \\
\hline & & قبلى & بعدى & قبلى & بعدى & & \\
\hline دالة & IT,IV & $.0 r$. & $\cdot, \leqslant 9 \wedge$ & $r, v$. & $\varepsilon, 7$. & 0 & تحديد المشكلة \\
\hline دالة ل & 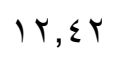 & .071 & $\cdot, 0 \cdot \mathrm{V}$ & $r, T$. & $\varepsilon, 07$ & 0 & جمع المعلومات \\
\hline دالة ل & $1 V, 1 \leq$ & $.0 V Y$ & $\cdot, \leqslant 9$. & r,o. & $\varepsilon, 7 T$ & 0 & فرض الفروض \\
\hline دالة & $1 \leq, 70$ & .701 & $\cdot, 0 \cdot V$ & $r, 0$. & $\varepsilon, 0$. & 0 & اختبار صحة \\
\hline دالة & $17, \wedge$ & $\cdot, V Y V$ & • ror & $r, 07$ & $\varepsilon, \wedge$. & 0 & التعميم \\
\hline دالة & $(1, \pi)$ & 1,001 & $1,1 Y \varepsilon$ & $I M, Y Y$ & $r \mu, 1$. & Yo & الاختبار ككل \\
\hline
\end{tabular}

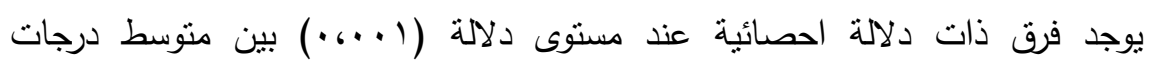
المعلمين المجموعة التجريبية في التطبيق البعدي لاختبار دهارات حل المشكلات ككل دله دله دله (23.10)، ومتوسطدرجاتهم في التطبيق القبلي(13.22) لصالح التطبيق البعدي.

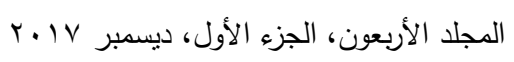


أنه يوجد فرق ذات دلالة احصائية عند مستوى دلالة (1 (.،.) بين متوسط درجات

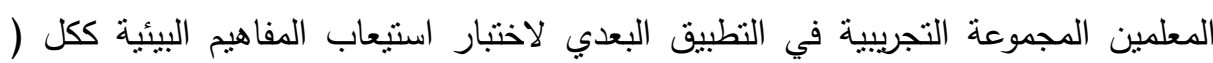
المعرفي و مقياس التعاطف ومعرفة الذات) (33.10)، ومتوسطدرجاتهم في التطبيق لئنيق

القبلي(14.74) لصالح التطبيق البعدي.كما بالجدول (v). جدول(V): قيمة (ت) لالالة الفروق بين منوسطي درجات المجموعة التجريبية

\begin{tabular}{|c|c|c|c|c|c|c|c|}
\hline \multirow{2}{*}{ مستوية } & \multirow{2}{*}{ قيم ت } & \multicolumn{2}{|c|}{ الانحراف المعياري } & \multicolumn{2}{|c|}{ المتوسط } & \multirow{2}{*}{ الالارجية } & \multirow{2}{*}{ المستوى } \\
\hline & & قبلى & بعدى & قب!ي & بعدى & & \\
\hline دالة & r & 1,17 & $\cdot, \leqslant q$. & $\varepsilon, r T$. & $9, \pi>7$ & 1. & الشرح \\
\hline دالة & $\mid \Lambda, \vee \top$ & 1,74 & $\cdot, \leqslant 9 \wedge$ & $r, v$. & $q, \varepsilon$. & 1. & التقسير \\
\hline دالة & ro, 1 . & $\cdot, \wedge \wedge \mathrm{T}$ & $\cdot, T \vee \wedge$ & $r, \wedge$. & $V, 07$ & $\Lambda$ & التطبيق \\
\hline دالة & $1 r, \cdot 9$ & $1, r V$ & $\cdot, \varepsilon \Psi$. & 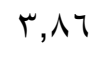 & $7, \vee \vee 4$ & V & المنظور \\
\hline دالة ب ل مالة & $r ч, r$. & $\varepsilon, 1 \varepsilon$ & $1, \cdot r$ & $1 \varepsilon, V \varepsilon$ & $r \mu, 1$. & ro & ككن الاختبار \\
\hline & & & & & 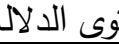 & & \\
\hline
\end{tabular}

جدول(^): قيم معاملات الارتباط بين اختبارالمفاهيم البيئة واختبار حل المشكلات ومقياس

\begin{tabular}{|c|c|c|c|}
\hline & & & التعاطف \\
\hline معرفة الأات & اختبار مهارات حل & المفتاريم البتيئية & الاختبار \\
\hline • & $\cdot, \vee \vee 4$ & 1 & استيعاب كليا هيم البيئة \\
\hline$\cdot, \mathrm{v})$ & $T$ & $\cdot, \vee \vee 7$ & مهارات حل المشكلات \\
\hline
\end{tabular}

- أنه توجد علاقة ارتباطية موجبة دالة عند مستوى 0 .,. بين درجات اختبار استيعاب

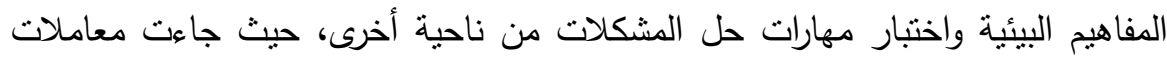

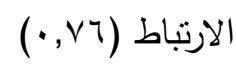

- وتوجد أيضًا علاقة ارتباطية موجبة دالة عند مستوى 0 ., • بين درجات اختبار حل

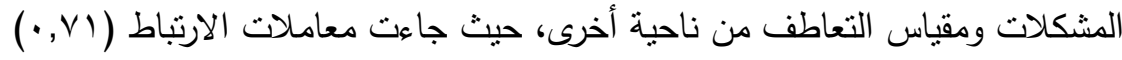


- كما توجد علاقة ارتباطية موجبة دالة عند مستوى 0 ., • بين درجات اختبار استيعاب

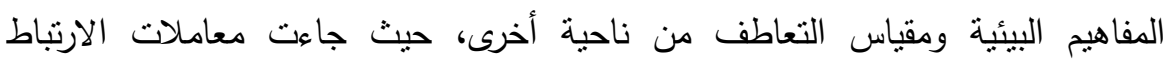

وقد اتفقت العديد من الدراسات التي تتاولت الاستيعاب المفاهيمي وأكدت على تتميته من

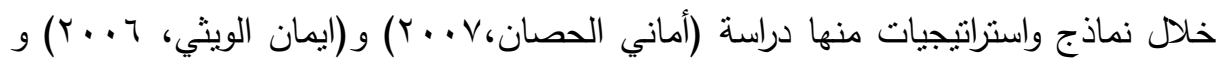

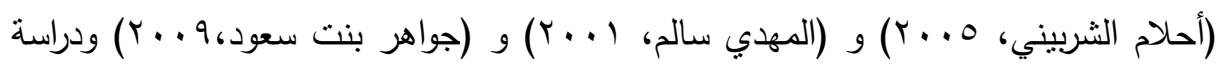
(Kalkaris etal.,2003)

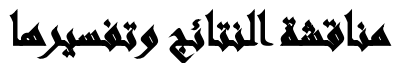

أوضحت متوسطات درجات معلمي الكيمياء في التطبيق القبلي لاختبار مهارات حل

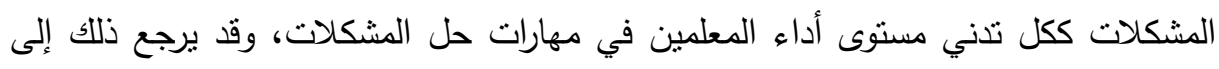
الأسباب النالية: ا. إهمال كثير من برامج التتمية المهنية التي تقدم لمعلمي الكيمياء التركيز على تطبيق مهارات حل المشكلات على مادة الكيمياء.

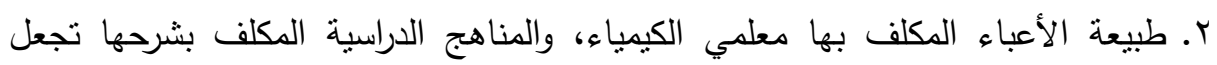
المعلم يهمل الاطلاعً على النماذج التدريسية الحديثة وكيفية تطبيقها.

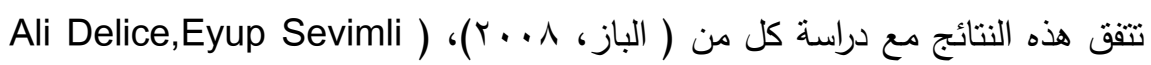

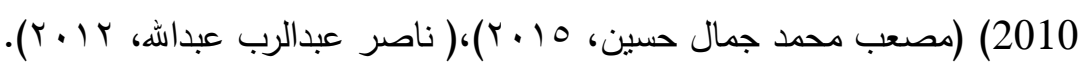
أوضحت منوسطات درجات معلمي الكيمياء - مجموعة البحث- في التطبيق القبلي لاختبار استيعاب المفاهيم البيئية ككل ومقياس التعاطف ومعرفة الذات تدني مستوى أداء المعلمين في كل مستوى من مستويات الاستيعاب المفاهيم البيئية، وقد يرجع ذلك إلى الأسباب التالية: ا ـ قصور كثير من برامج التتمية المهنية التي تقدم لمعلمي الكيمياء التركيز على استيعاب

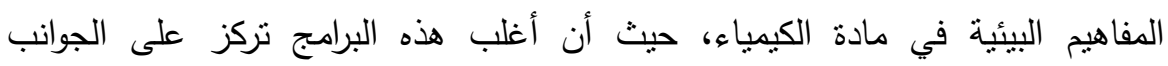
التذريسية أو نركز على شرح للمحتوى العلمي فقط.

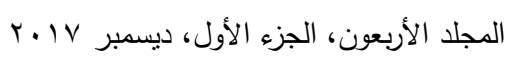


r. طبيعة الأنشطة التي تقدم لمعلمي الكيمياء سواء داخل هذه البرامج أوغيرها، لاتركز على استبعاب المفاهيم البيئية لديهم.

يمكن أن تعزى ايضاً إلى ممارسة المعلمين مجموعة من الأنشطة والاستقصاءات لهئر والبحث عن المعرفة والعلاقات بأنفسه وايجاد حلول خلال تتفيذ مراحل التدريب، وهذا يتفق دنق مع دراسة كل من (falconer,etal,1994) و (costa,2001) وتتوافق مع ما انشترطة بيكنز

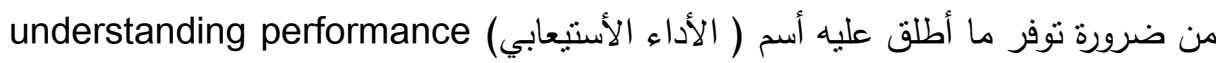

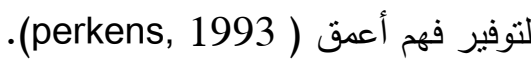
توجد علاقة ارتباطية موجبة دالة عند مستوى ه ., • بين درجات كل من اختبار المفاهيم

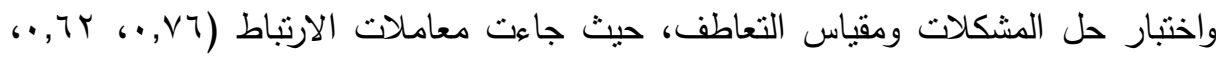

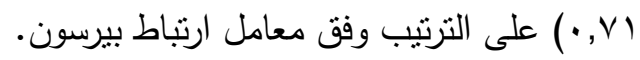

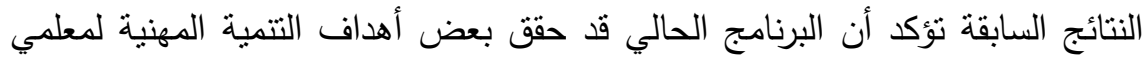

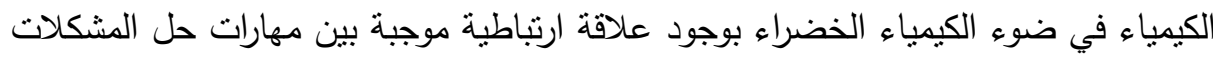
واستيعاب المفاهيم البيئية مما يجعله أكثر نقة بنفسه عند تقديم المحتوى لطلابه،وكذلك نقوم باعداد معلم قادر على استخدام مهارات حل المشكلات واستيعاب المفاهيم البيئية مطبقا

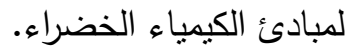

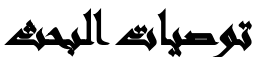

من خلال ما توصل إليه البحث من نتائج يمكن تقديم التوصيات التالية: ا. إعادة النظر في برامج التتمية المهنية التي تقدم لمعلمي الكيمياء بحيث تسعى هذه البرامج إلى إعداد معلم الكيمياء يتمكن من مواجهة المشكلات البيئية. r. ضرورة الاهتمام بتتمية استيعاب المفاهيم البيئية لدى معلمي الكيمياء كأساس التتمية المهنية لمعلمي الكيمياء في العصر الحالي. 


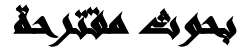

كثف البحث الحالي من خلال الإجراءات وماتوصلت إلية من نتائج عن وجود عديد من المشكلات التي لا تزال في حاجة إلى البحث ومن الضروري وضع مقترحات لها.وقد تمنلت هذه فيما يلي: 1. إعداد برنامج مقترح للطالب المعلم بكليات التربية قائم على الكيمياء الخضراء. r. إجراء بحوث ممانتة للبحث الحالي بحيث تنتاول متغيرات أخرى منل ( عمليات العلم -

$$
\text { التفكير الناقد - تقدير العلم والعلماء - مهارات التفكير الاستراتيجي). }
$$

\section{المرائي}

آمال محمد(ب ( ب): فاعلية وحدة مقترحة فى الكيمياء الخضراء بمقرر الكيمياء في تتمية المفاهيم والاتجاهات البيئية لطلاب المرحلة الثابة الثانوية، رسالة دكتوراة، معهد الثراء

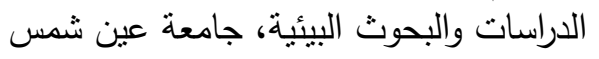

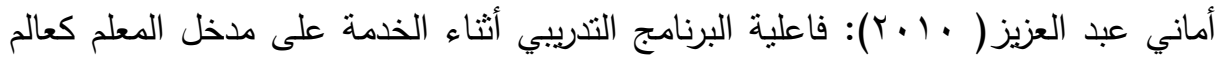

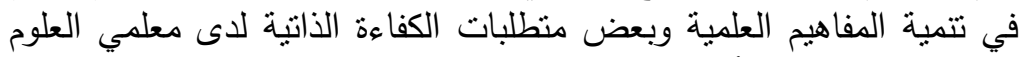

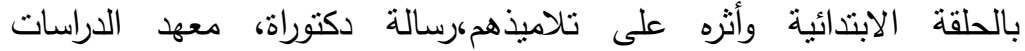
التربوية،جامعة القاهرة.

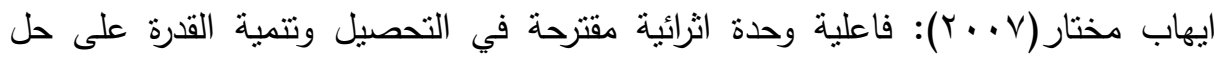

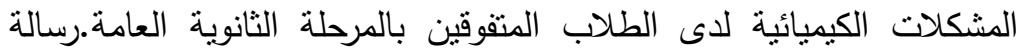

$$
\text { ماجستير، كلية التربية جامعة المنصورة. }
$$

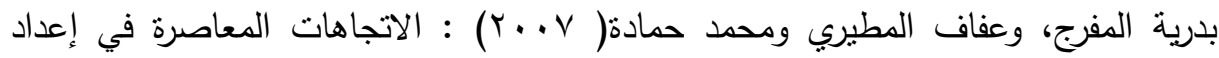

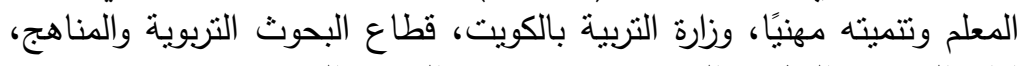

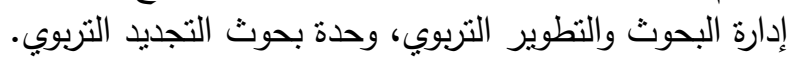

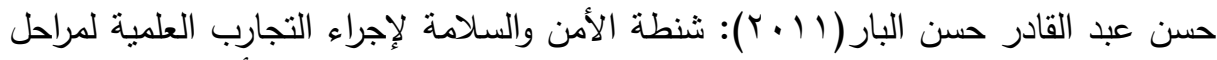

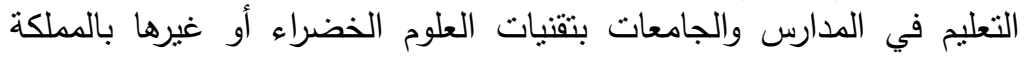

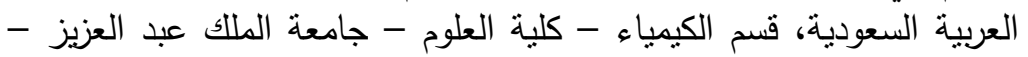




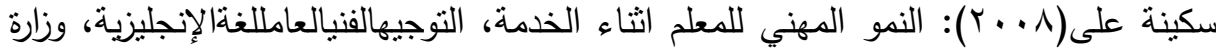

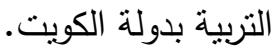

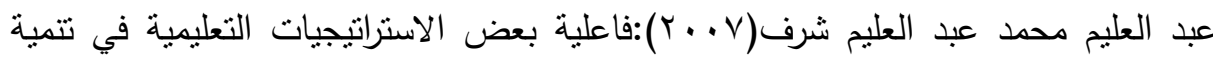

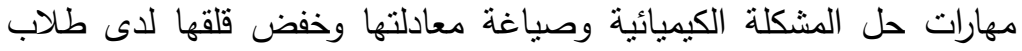

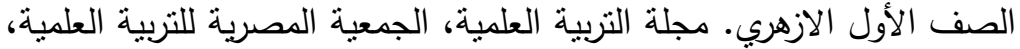

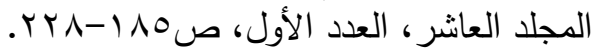

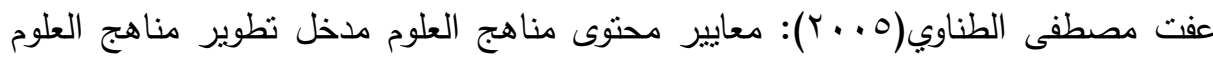
بالمرحلة الاعدادية، المؤتمر العلمي التاسع للجمعية المصرية للترية للتربية العلمية

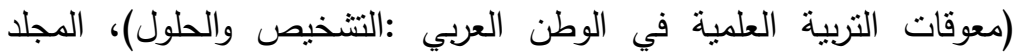
الأول، الإسماعيلية، آليوليو - r أغسطس.

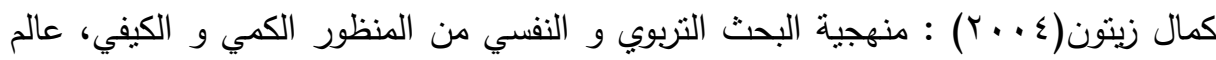

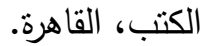

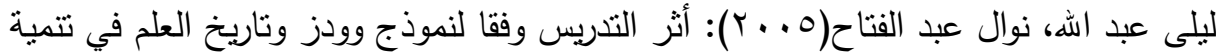

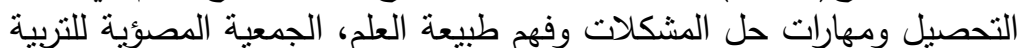
العلمية، مجلة التربية العلمية، المجلد الثامن، العدد الثالث.

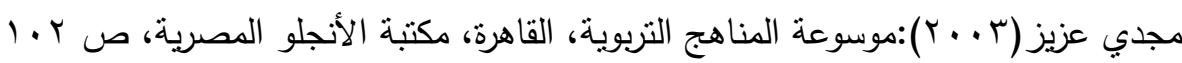

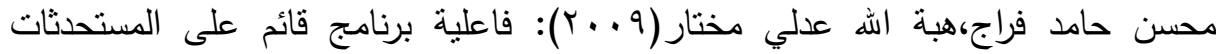

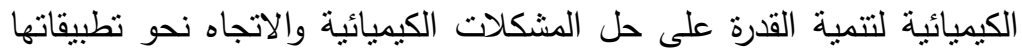

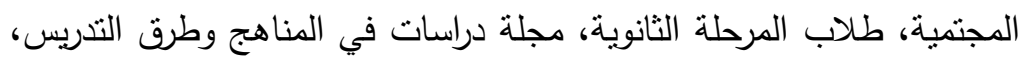

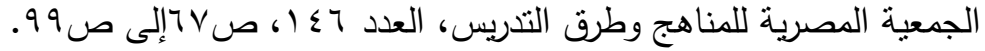

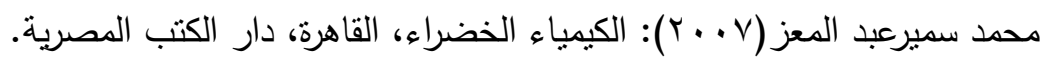

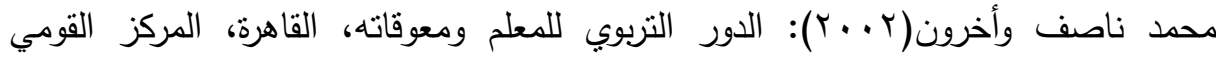
اللبحوث التربوية والتنمية.

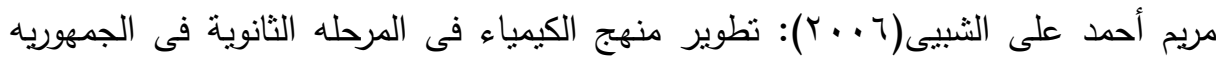

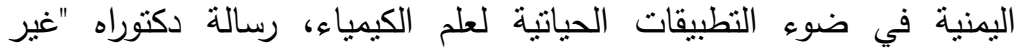
منشورة"، كليه التربية، جامعة عين شمس.

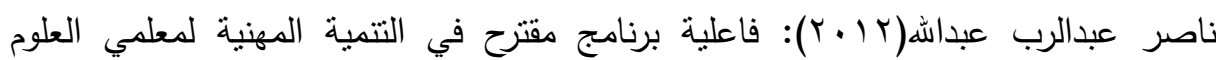
بالمرحلة الإعدادية بالبحرين و أثره في مهارات التقكير لدى تلاميذهم، دكتوراه. 
محمد سمير عبد المعز وآخرون

$$
\begin{aligned}
& \text { جامعة القاهرة - معهد الدراسات والبحوث التربوية - قسم المناهج وطرق } \\
& \text { التدريس } \\
& \text { هبة فؤاد سيد أحمد(T ( • ب): فاعلية تدريس وحدة في ضوء توجهات STEM لتتمية مهارات }
\end{aligned}
$$

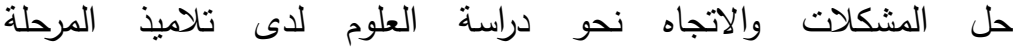

$$
\begin{aligned}
& \text { الأبتدائية،الجمعية المصرية للتربية العلمية، مجلة التربية العلمية، المجلد التاسع }
\end{aligned}
$$

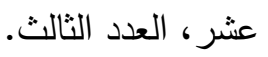

$$
\begin{aligned}
& \text { وزارة التربية والتعليم(؟ . . ץ): المعايير القومية للتعليم في مصر ، المجلد الأول، الأمل للطباعة }
\end{aligned}
$$

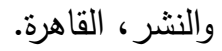

Hjeresen, Dennis L Schutt, David L, Boese Jinnee( 2002) Green, "Chemistry and Education". Journal of Chemical Education, v(177), n(12); p 1543.

KarenM.\&Alec B, ,( 2008) promoting inquiry - based sciences instruction : the validationof the science teacher inquiry rubric( STIR),jornal of the science education , 15(2),Pp3949.

Kauffman (2005):. Math and Science Education Focus Groups: Summary Kronley of Associates.

Marc A Kingshirn and Gary O spessard(2009):Green Chemistry Education. Chapter 5, pp 79-92.

Marzano,et al (2001):classroom instruction that works :Research-based strategies for increasing student achievement.

Marzano,et al (2003):What works in the school?:Reaserch-association for supervision and curriculum development,1703n.peauregard st. alexendria, USA.

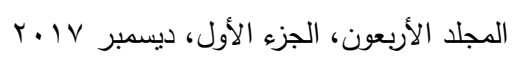




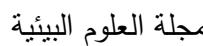

معهد الدراسات والبحوث البيئية - جامعة عين شمس لمس لمس

\title{
PROGRAM FOR PROFESSIONAL DEVELOPMENT \\ CHEMISTRY TEACHERS OF HIGH SCHOOL BASED \\ ON GREEN CHEMISTRY AND ITS IMPACT ON \\ DEVELOPMENT OF PROBLEM SOLVING SKILLS \\ AND ASSIMILATION THE ENVIRONMENT \\ CONCEPTS
}

\begin{abstract}
Abdel Moez, M. S. ${ }^{(1)}$; Ahmed, O. J. ${ }^{(1)}$ and Al-Shami, Sahar, I. M. ${ }^{(2)}$ 1) Faculty of Education, Ain Shams University 2) Curriculum expert, Ministry of education
\end{abstract}

\begin{abstract}
The objective of the research is to design a training program for the professional development of secondary chemistry teachers based on the development of problem solving skills and assimilation of environmental concepts. The researcher designed the program and its tools which were in the list of problem solving skills, the list of environmental concepts that should be absorbed for chemistry teachers, Solving problems, and testing the assimilation of environmental concepts by conducting tribal measurements and then implementing the program and re-measuring again after implementation. The results were to show the effectiveness of the program in developing the skills of solving problem solving skills and developing comprehension of problems The researcher found that there are statistically significant differences between the average scores of the pre-and post-tribal experimental groups in favor of the post-application in the problemsolving skills test, It also found that there are statistically significant differences between the mean scores of the experimental and tribal experimental groups in favor of the post-application in testing the understanding of environmental concepts .Therefore, it recommends 378

$$
\text { المجلد الأربعون، الجزء الأول، ديسمبر VIV }
$$
\end{abstract}


محمد سمير عبد المعز وآخرون

reconsidering the professional development programs of chemistry teachers by directing the attention of green chemistry researchers, who seek to provide the teacher with problem solving skills and understanding of environmental concepts.

Key Words: Program for professional development chemistry teachers- green chemistry - problem solving skills - assimilation the environment concepts. 